\title{
Waste generation and the economic cycle in European countries. Has the Great
}

\section{Recession decoupled waste and economic development?}

\author{
Alejandro Alcay ${ }^{1}$, Antonio Montañés ${ }^{2}$ and María-Blanca Simón-Fernández ${ }^{3}$ \\ ${ }^{1}$ University of Zaragoza, Spain. alcay@unizar.es \\ ${ }^{2}$ University of Zaragoza, Spain. amontane@unizar.es \\ ${ }^{3}$ University of Zaragoza, Spain. bsimon@unizar.es
}

\begin{abstract}
This paper studies the relationship between waste generation and economic development for a sample of European countries. In contrast to previous studies that have considered this relation to be stable over time, we apply methods for testing the presence of structural breaks located at unknown periods. This methodology provides robust evidence against the stability of the relationship, finding ruptures in the so-called dot.com crisis, in the early 2000s, and in episodes related to the Great Recession. Once these breaks are considered, we observe that waste generation shows considerable dependence on the evolution of the economy for those countries with the lowest per capita income levels. This suggests the existence of a trade-off between convergence policies and those aimed at avoiding environmental degradation, suggesting the need to maintain and reinforce environmental policies in the EU.
\end{abstract}

- Keywords: Waste decoupling, circular economy, great recession, green growth

Highlights

- The relationship between waste generation and economic growth is not stable.

- Structural breaks are found around the 2000s and the Great Recession.

- The recovery after the Great Recession has slowed down waste prevention.

- Economic convergence policies have been favored over environmental policies. 


\section{Introduction}

The search for the delicate balance between economic growth and sustainability has been one of the core issues on the agendas of politicians and decision-makers in recent years. The underlying idea is that economies should be able to maintain sustained growth over time, but consuming fewer natural resources and avoiding the degradation of the environment. This goal is not always easy to achieve and therefore supranational entities such as the United Nations or the European Union have spared no efforts in this respect, drawing up various recommendations for their member states with the common objective of preserving the environment. Examples are the MDGS (Millennium Development Goals), replaced by the later SDGs (Sustainable Development Goals) of the UN. In particular, the aim of Target 12.5 of the SDGs is to substantially reduce waste generation through prevention, reduction, recycling, and reuse.

The 7th Environmental Action Plan (EAP) introduced by the EU in 2014 follows similar lines. Once again, one of the objectives set within this plan is to reduce the adverse effects of municipal waste on the environment via the promotion of a circular economy, with a special focus on turning waste into a resource, with more prevention, re-use and recycling. This EAP program was followed by the launch in 2020 of the new Circular Economy Action Plan for a Cleaner and More Competitive Europe (CEAP). Section 4.1 is entitled "Enhanced waste policy in support of waste prevention and circularity".

A simple reading of these programs reveals that one of the principal environmental preservation measures is the reduction of waste generated, seeking to decouple environmental degradation and economic growth. This idea of decoupling applies not only to the generation of waste. In general, the programs seek to encourage sustainable economic growth, which is none other than growth which does not generate 
environmental degradation. Given that this is a crucial factor in all Green policy, it is not surprising that the literature analyzing the relationship between economic growth and environmental degradation has grown significantly, mostly focusing on carbon dioxide emissions. For instance, we can cite the papers by Wang and Wang (2019) on the USA case, Zhao et al. (2017) on the Chinese case, Shuai et al. (2019) on a sample of 133 countries, and Chen et al. (2018) on the OECD countries. A summary of these results can be found in Haberl et al. (2020).

The importance of the effects of waste generation on environmental degradation has attracted the attention of several researchers who have analyzed the relationship between waste generation and economic growth in recent years, ranging from the seminal paper by Johnstone and Labonne (2004) to the most recent studies by Gardiner and Hajek (2020), Mazzarano et al. (2021), and Magazzino et al. (2021). The conclusions reached by this distinguished body of work are far from robust in the sense that, although the nexus between waste generation and economic growth appears to be established, the debate about the intensity and the direction of this relationship is far from over.

A possible explanation of the variation in the results may be the fact that the relationship between these variables has been estimated under the assumption of parameter stability. However, we should note that this hypothesis might not hold, given that certain events can alter it. A very recent example is the so-called the Great Recession, but there are several previous examples such as the Great Crash (1929), the oil shock (1973), or the dot.com crisis (2004), amongst others. Whilst the impact of these events on the evolution of socioeconomic indicators has frequently been analyzed, there is little evidence (if any) of their effect on waste generation and on the waste generation/economic growth link. As a consequence, as Namlis and Komilis (2019) suggest, it seems appropriate to reevaluate the waste/economic growth relationship under the prism of the possible presence of 
changes in their parameters. We should note that estimations may be biased if these breaks are not included in the model specification and, consequently, the conclusions drawn from them could be open to question.

Against this background, the aim of the paper is to study the relationship between waste generation and economic growth in EU countries by considering that the hypothesis of parameter stability may not hold. The relaxation of this hypothesis can help us to capture the effect of the Great Recession, as well as other crises occurring during the sample period, on waste generation. Consequently, the standard specifications are no longer adequate. Rather, we should employ econometric methods that allow for the presence of structural breaks in the parameters of the model.

In our view, the procedure defined in Bai and Perron (1998, 2003a, 2003b) is a very appropriate one, given that it has the advantage of endogenously determining both the number of structural breaks and the period during which these structural breaks appear. Furthermore, we employ two different variables to capture the economic evolution of the countries. On the one hand, we employ the per capita Gross Domestic Product (GDP), which is the most standard measure. On the other hand, we also use the Human Development Index (HDI), also employed in Namlis and Komilis (2019), given that this variable is also correlated with waste generation and provides a different view on the evolution of society, more related to the idea of wellbeing.

The article is organized as follows. Section 2 provides a brief overview of the main publications addressing the analysis of the relationship between waste generation and economic evolution. Section 3 presents the methodology and the data. The main results are reported in Section 4 and discussed and analyzed in Section 5. The main conclusions are given in Section 6. 


\section{Literature review}

This Section presents a brief review of the recent contributions to the literature attempting to explain the evolution of waste generation as a function of economic growth. In this regard, we should first note that the relationship between environmental degradation and economic development has become an important component of the objectives and policies proposed by international institutions such as the United Nations, the OECD, and the European Union. As a consequence, the interest in analyzing the environmental effects of economic growth and evaluating possible public policies has generated substantial literature. The specific case of waste generation has not escaped this tendency as reflected in the growing interest in the analysis of the relationship between waste generation and economic growth.

The most commonly employed variable to measure waste generation is the municipal solid waste (MSW), whose relationship with respect to economic growth (mostly measured by GDP) has been extensively addressed in the literature since the seminal paper by Johnstone and Labonne (2004), who studied the case of 30 OECD countries. This work was subsequently followed by a large number of similar works, most of them focused on European countries. Examples are Namlis and Komilis (2019), Vujić et al. (2015), Mazzarano et al. (2021), and those by Gardiner and Hajek (2017, 2020a), amongst many others. Similar studies focusing on countries outside Europe include Tao et al. (2008) and Gui et al. (2019) on the case of China, Jebli and Youssef (2015) on the case of North African countries, and Yllmaz (2020) on the OECD countries. We should also note excellent reviews of the literature, including those by Gardiner and Hajek (2020b), Boubellouta and Kusch-Brandt (2020), and Magazzino et al. (2021). 
All these papers employ a linear relationship between MSW and different socioeconomic indicators, with the GDP being the most commonly used. However, another group of papers base their study on the use of a non-linear specification, clearly related to the very general proposal of Kuznets (1955), which was particularized to the environmental case in Grossman and Krueger (1995). For example, Mazzanti and Zoboli (2008, 2009), Montevecchi (2016), Ercolano et al. (2018), Madden et al. (2019), and Cheng et al. (2020) examine the so-called Waste Kuznets Curve (WKC) ${ }^{1}$. However, the evidence in favor of the WKC is far from robust. Moreover, we should note that Baalbaki and Marrouch (2020) cannot find evidence in favor of this curve when using a much more general approach based on the use of the flexible polynomial specification of Wang (2013), which nests the WKC model. This result seriously queries the existence of this WKC, as Aslanidis and Iranzo (2009) also note for the general environmental Kuznets Curve.

The analysis of the literature in this field leads us to conclude that the link between waste generation and economic growth remains an issue for open debate ${ }^{2}$. A possible reason for the lack of unanimity in the conclusions may lie in the fact that the relationships between waste generation and economic growth has been estimated under the assumption of stability of the parameters. However, this assumption is somewhat dubious, given that some events (such as the previously mentioned Great Recession) may have affected the waste generation/economic growth relationship. Then, a possible way to reconcile this amalgam of very different results is the relaxation of the hypothesis of parameter stability, allowing for the parameters of the model to change. In this regard, we should note that the presence of structural breaks has not been considered in the literature, ignoring the fact that the flexibility provided by the inclusion of these breaks may help us to better understand the nature of the waste generation-economic growth nexus. 
The following sections are thus devoted to an analysis of the relationship between waste generation and economic growth under the scope offered by the presence of structural breaks.

\section{Material and methods}

\subsection{Data source}

As mentioned above, the aim of this paper is to analyze the relationship between the generation of waste and the evolution of the EU economies. The data employed to that end are data of per capita municipal solid waste (MSW) as a measure of waste generation. This variable also provides us with a useful approximation to environmental degradation, in that it reflects not only the consumption patterns of a country's population, but also the environmental awareness, and the adoption of industrial environmental practices by companies when designing products and packaging.

In order to measure the evolution of the economies, we employ the per capita GDP, which is the most standard variable employed to that end. However, we also use the HDI. The inclusion of this variable, in line with previous works (Namlis and Komilis, 2019; SanyéMengual et al., 2019; Kalimeris et al., 2020), is to strengthen the welfare dimension provided by GDP with a broader vision of development covering elements such as education or the health of societies.

The MSW and GDP data have been obtained from the Eurostat database (Eurostat, 2019), whilst the data of the HDI have been collected from the World Development Indicators database. European Union countries were selected for which we had substantial information during the period $1995-2018^{3}$. The final sample is composed of the following countries: Austria, Belgium, Bulgaria, Cyprus, Czechia, Denmark, Estonia, Finland, France, Germany, Greece, Hungary, Ireland ${ }^{4}$, Italy, Latvia, Lithuania, Luxembourg, 
Netherlands, Poland, Portugal, Romania, Slovakia, Slovenia, Spain, Sweden and United Kingdom. We have additionally considered the data of the total EU27 when available (MSW and GDP).

Table A1 reflects some descriptive statistics of the variables. As we can observe, the per capita MSW of the EU27 was 492 kilograms in 2018, somewhat greater than the value at the beginning of the sample (465 kilograms). Then, we can observe a slight growth. This increment is not homogeneous, given that we can observe that Bulgaria $(-2.1 \%)$, Germany $(-0.1 \%)$, Hungary $(-0.8 \%)$, Netherlands $(-0.2 \%)$ Romania $(-1.0 \%)$, Slovenia $(-0.9 \%)$ and Spain $(-0.3 \%)$ show negative growth rates, whilst Austria (1.2\%), Denmark (1.7\%), Finland (1.3\%), Greece (2.3\%), Latvia (1.9\%), Portugal (1.6\%) and Slovakia $(1.5 \%)$ show growth above $1 \%$.

This heterogeneous behavior is maintained if we split the sample into two subperiods, 1995-2007 and 2007-2018, in order to analyze the possible effect of the GR. We can now observe that the generation of per capita MSW in the EU27 increased by $0.9 \%$ in the period before the GR, while it decreased at a rate of $-0.5 \%$ after it. But even this result is not common to all countries, since there are countries that decreased their waste generation before the GR, mainly Bulgaria (-1.9\%), Slovenia (-1\%) and Germany (0.6\%), while Austria (2.6\%), Denmark (3.5\%), Latvia (3.3\%), Portugal (2.5\%) and Sweden (2\%) increased their waste by above $2 \%$. After the GR, most countries decreased their waste, although some increased it substantially, as is the case for Czechia (1.6\%) and Slovakia (3.2\%). The increase in the generation of waste generally occurs in the recovery period 2014-2018. Therefore, the results are far from being homogeneous, even despite the great effort that has been made by the EU Commission for harmonization and coordination in the fight against waste generation. 
This heterogeneity also appears when considering the economic growth of the countries. The per capita GDP of the EU27 as a whole grew at an average of $1.5 \%$ per year during the period 1995-2018. However, there are countries that grew much faster, such as Ireland (4.1\%), Poland (4.1\%), Estonia (4.6\%), Latvia (5.1\%) and Lithuania (5.4\%), while other countries like Italy $(0.3 \%)$ or Greece $(0.7 \%)$ did not reach $1 \%$. Likewise, growth before the GR was $2.2 \%$ in the EU27 as a whole, while this figure was much more moderate $(0.7 \%)$ after the GR and was even negative for countries such as Greece (-2.6\%), Italy (0.7\%), Cyprus (-0.6\%), Finland (-0.1\%) and Luxembourg (-0.1\%). Moreover, we can appreciate notable differences between the 2007-2014 and the 2014-2018 periods. We also observe that all countries experienced positive growth above $1 \%$ in the period 2014 2018.

The HDI data are much more homogeneous, partially due to the bounded construction of this indicator, which takes values in the $(0,1)$ interval. However, despite this, they do show slight variations both by country and by period. The average HDI of the EU27 countries included in the sample grew at an average rate of $0.6 \%$ throughout the sample period, although the growth was $0.8 \%$ before the GR and only $0.4 \%$ afterwards. Over the entire period, the growth in some countries was very meagre. Belgium, France and the Netherlands had an average growth rate of $0.3 \%$, while Estonia, Latvia and Lithuania were around $1.0 \%$. Likewise, the growth rate after GR was clearly lower, especially in countries such as Belgium, Finland, France, Germany, Italy and Luxembourg with increases of $0.2 \%$.

The previous descriptive analysis sustains our initial idea of the possible presence of structural breaks related to GR in the relationship between per capita MSW, HDI and the evolution of the economy. The following section analyzes this issue more deeply using more powerful econometric methods. 


\subsection{Testing for structural breaks}

Following the seminal works of Grossman and Kreuger (1995) and Holtz-Eakin and Selden (1995), our starting model is the linear relationship between MSW and GDP:

$\ln (\mathrm{MSW})_{\mathrm{it}}=\alpha_{\mathrm{i}}+\beta_{\mathrm{i}} \ln \left(\mathrm{GDP}_{\mathrm{it}}\right)+\mathrm{e}_{\mathrm{it}, \mathrm{i}} \mathrm{i}=1, \ldots, 31, \mathrm{t}=1995, \ldots, 2018$

As Grossman and Krueger (1995) note, this model is a reduced form that has the advantage of summarizing the net effect between the two variables. It also has some limitations, such as the absence of information of why this relationship exists. In any event, this is a standard specification, which is commonly employed in the literature.

This model considers that its parameters cannot change over time. This is quite a questionable restriction, especially if we take into account some events, such as the GR, that could have affected this relationship by modifying the value of the GDP elasticity. Therefore, it seems necessary to adapt the previous model to the presence of structural breaks.

We can employ several econometric tools to that end, but we consider that the methodology developed by Bai and Perron $(1998,2003 a, 2003 b)$ is the most suitable given its flexibility and good performance even with samples like the one we have in this

paper $^{5}$. This methodology has the advantage of endogenously determining the number of breaks, as well as the period when these breaks occur. This is based on the estimation of the following model:

$\ln (\mathrm{MSW})_{\mathrm{it}}=\alpha_{\mathrm{ij}}+\beta_{\mathrm{ij}} \ln \left(\mathrm{GDP}_{\mathrm{it}}\right)+\mathrm{v}_{\mathrm{it}}, \mathrm{i}=1,2, \ldots, 31, \mathrm{t}=\mathrm{TB}_{\mathrm{j}-1}, \ldots, \mathrm{TB}_{\mathrm{j}}, \mathrm{j}=1, \ldots, \mathrm{m}+1$

where $\mathrm{TB}_{\mathrm{j}}$ means the period where the breaks appear, with $\mathrm{TB}_{\mathrm{o}}=1995$ and $\mathrm{TB}_{\mathrm{m}+1}=2018$, $\mathrm{m}$ being the number of breaks, and $\mathrm{v}$ an innovation that can follow a wide range of stationary models, including the general ARMA model. We should note that the variance 
of this innovation need not be constant and, therefore, breaks in variance are considered provided they occur at the same dates as the breaks in the parameters of the regression ${ }^{6}$.

The Bai-Perron (BP) procedure involves the estimation of the above equation, considering that the break may appear at any point in the sample. A Chow-type test is then defined in order to determine the existence of the first break. The estimation of the period where this first break occurs coincides with the period where the Chow-type statistic attains its maximum value. The presence of multiple breaks can be analyzed by using the $\mathrm{UD}_{\max }$ and $\mathrm{WD}_{\max }$ statistics which test the null hypothesis of no structural breaks versus the presence of an unknown number of breaks.

The number of breaks has been estimated by considering a maximum value of 3 breaks and subsequently applying the sequential procedure defined in Bai and Perron (1998), combined with the repartition method described in Bai (1997). In those cases where the $\mathrm{UD}_{\max }$ and $\mathrm{WD}_{\max }$ reject the non-structural break null hypothesis but the sequential method cannot find any break, we have determined the number of breaks by using the statistics proposed by Schwarz (1978). Finally, we have used the quadratic spectral kernel to take into account the presence of possible autocorrelation and heterogeneity in the perturbations, combined with the Andrews (1991) automatic bandwidth selection with an $\mathrm{AR}(1)$ approximation.

Given that the Bai-Perron procedure only works correctly once regime-wise stationarity is proved, we are limited to applying it to those cases where the unit root null hypothesis has been previously rejected. Thus, an appropriate strategy should be based, first, on the application of the unit root tests and, once stationarity is shown, we should then apply the BP procedure for estimating the number of breaks, the periods where the breaks appear and, finally, the mean of the variable of each of the regimes. 
We should note that some papers have previously analysed the relationship considered in (1) by employing the so-called Waste Kuznets Curve, as mentioned above. Then, we have also adapted the WKC model to admit the presence of structural breaks and we have additionally estimated the following equation:

$\mathrm{MSW}_{\mathrm{it}}=\alpha_{\mathrm{i}}+\beta_{\mathrm{i}} \mathrm{GDP}_{\mathrm{it}}+\gamma_{\mathrm{i}} \mathrm{GDP}^{2}{ }_{\mathrm{it}}+\mathrm{e}_{\mathrm{it}, \mathrm{i}} \mathrm{i}=1, \ldots, 31, \mathrm{t}=1995, \ldots, 2018$

A comparison shows that the results obtained from the estimation of model (2) clearly outperform those of model (3) when, for instance, we compare both estimations by using the information criterion proposed in Schwarz (1978), even if we admit the presence of structural breaks in (3). As a consequence, the results of the estimation of the WKC models will be omitted and we will focus exclusively on the estimation of model (2).

Finally, as previously mentioned, we will also consider the relationship between the waste generation and the HDI, by simply substituting HDI for GDP in equation (2).

\section{Results}

\subsection{Unit root inference}

As a previous step to using the BP methodology, we have mentioned that we should first analyze the time properties of the variables included in equation (2). If we can reject the unit root null hypothesis, then we will be able to apply this methodology. The unit root inference has been based on a specification that includes an intercept and a trend. Additionally, we have used the quasi-generalized least squares detrending method proposed by Elliot et al. (1996), instead of using the standard statistics proposed in Dickey and Fuller (1979) which are based on the ordinary least squares estimation. Furthermore, we have considered the possible presence of several breaks in the trend function, in order to avoid the bias caused by ignoring them; see Perron (1989) in this regard. Then, we 
have employed the statistics proposed by Carrion-i-Silvestre et al. (2009), considering a maximum value of 3 breaks. Examples of the use of these statistics for environmental variables can be found in Cai et al. (2018), Yilanci et al. (2019) and Churchill et al. (2020). The results are presented in Tables A2, A3 and A4.

We first observe that the evidence against the unit root null hypothesis is scarce when the presence of broken trends is not considered. However, the inclusion of breaks in the trend function changes this picture and the evidence against this hypothesis is robust for the three variables under consideration. Nevertheless, there are some exceptions. We cannot reject the presence of a unit root for the per capita MSW in the case of Italy. However, if we exclude the last observation, we find robust evidence against it and, therefore, we will maintain this country in the analysis.

The absence of evidence against the unit root hypothesis for the GDP of Hungary and Romania is more problematic, even if we consider a liberal $10 \%$ significance level. Similarly, we have not been able to reject the unit root null hypothesis for the HDI of Finland. Although we should omit the results of these countries, we will maintain them to facilitate the comparison of their results with those of the rest of the countries ${ }^{7}$.

We can also see that the breaks in the trend function can be grouped around three periods of time. The first appears around the year 2000 and is related to the burst of the dot-com bubble, also reflecting the introduction of new environmental policies aimed at waste prevention (European Parliament and Council Directive 1994/62/EC on packaging and packaging waste and the Council Directive 1999/31/EC on the landfill of waste). The other two breaks are connected (2008 and 2013) to the effects of the Great Recession, the fall in GDP worldwide and its later recovery. These results confirm our suspicion about the importance of the Great Recession in the evolution of the per capita MSW and, 
therefore, it seems advisable to analyze whether these breaks also affect the determinants of the MSW, which is the goal of the next section.

Once we have proved that the variables are not integrated, we can then apply the BP procedure to test for the presence of structural breaks in the relationship between waste generation and the two measures of the evolution of the economies that we have selected.

\subsection{MSW and GDP relationship: Is it stable?}

Tables 1 and 2 present the results of the application of the BP methodology to the GDPMSW and HDI-MSW relationships, respectively. These tables include information on the statistics that analyze the null hypothesis of parameter stability, the estimations of the parameters and their corresponding robust standard deviations, the periods where the breaks occur and some statistics for analyzing the goodness of the estimation.

We should first note that both $\mathrm{UD}_{\max }$ and $\mathrm{WD}_{\max }$ statistics always reject the null hypothesis of non-structural breaks. Therefore, none of these relationships is stable across the sample. The number and the periods when the structural breaks appear vary across the countries. However, we can observe that they are again concentrated in three periods of time, coinciding with those obtained from the unit root inference. Parameter $\beta_{\mathrm{j}}$ corresponds to the elasticity in each estimated sub-period $(\mathrm{j}=1,2,3,4)$. Figure 1 presents maps with the estimated elasticities in 1995, 2007 and 2018. We classify these elasticities into three groups: Absolute decoupling $\left(\beta_{\mathrm{j}} \leq 0\right)$, Relative decoupling $\left(0<\beta_{\mathrm{j}} \leq 1\right)$ and coupling $\left(\beta_{\mathrm{j}}>1\right)$.

If we analyze the estimated elasticities in Table 1 at the beginning of the sample, we can observe the range goes from -0.94 (Slovakia) to 2.28 (Greece), whilst the value for the total EU27 is 0.56. We can also appreciate that Slovakia, Slovenia, Bulgaria, and 
Germany show absolute decoupling, whilst Spain, Czechia, Sweden, Portugal, Denmark, Austria and Greece present elasticities greater than 1.

The estimated elasticities at the end of the sample are somewhat different. The range now goes from -0.89 (Belgium) to 2.67 (Slovakia). We can observe that Belgium, Luxembourg, United Kingdom, Netherlands, Bulgaria, Sweden, and Denmark present absolute decoupling of GDP elasticity, whilst Portugal, Poland, Slovenia, Greece, and Slovakia show a coupling relationship in the final estimated segment of the sample.

This initial analysis of the estimated elasticities denotes a clear heterogeneity in the results. In spite of this, it is true that the elasticity for the total EU27 does not show substantial changes, always taking positive values and pivoting at around 0.5.

If we compare the estimations of elasticities before and after the Great Recession, we can observe that some countries have clearly increased them. This is the case of Germany ($1.01,0.46)^{8}$, Poland $(-0.12,1.13)$, Slovakia $(0.37,2.67)$, Spain $(-0.50,0.55)$ and the United Kingdom $(-3.49,-0.58)$. By contrast, Denmark $(1.47,-0.07)$, the Netherlands $(0.24,-0.56)$ and Sweden $(0.66,-0.12)$ show a significant improvement during the recession.

Focusing on the decoupling process between GDP and MSW for European countries, the results shown in Table 1 reflect an improvement during the whole period in most cases. Bulgaria is the only country in which absolute decoupling is maintained, while Portugal is the only one that maintains a near coupling relationship. The decoupling process intensified during the 2000s for several countries, although it was brought to a halt by the economic crisis which, except for some countries that maintained the downward trend, resulted in a reduction of waste generation with respect to GDP. Sweden, Denmark, the United Kingdom and Luxembourg exhibit a more pronounced improvement. By contrast, 
Estonia, Slovakia and Slovenia experienced more intensive waste generation in terms of GDP. We can also observe that most countries exhibit relative decoupling. The EU27 average slightly improved over this period, showing a situation of relative decoupling.

Table 2 shows the results when considering the HDI as an indicator of wellbeing in EU countries. The values of the estimated elasticities are larger (in absolute terms) than those obtained for the MSW-GDP relationship. This can be easily understood if we take into account the fact that the HDI varied slightly, mainly due to its construction. Then, it comes as no surprise that the estimated elasticities may take somewhat large values (in absolute terms). The range of HDI elasticities at the initial estimated segment of the sample goes from -9.32 (Slovakia) to 8.82 (Austria). Likewise, Slovakia, Slovenia, Bulgaria, Belgium, and Germany exhibit absolute decoupling, the estimated values of Latvia and Estonia are small, and the rest of the countries exhibit estimated HDI elasticities greater than 1.

The results are somewhat different if we consider the elasticities of the final estimated segment. The range goes from -6.56 (Belgium) to 24.44 (Slovakia). We can also see that Austria, Belgium, Bulgaria, Denmark, Germany, Greece, Hungary, Ireland, Luxembourg, Netherlands, Romania, Sweden, and United Kingdom exhibit negative estimated elasticities, whilst Czechia, Estonia, France, Lithuania, Poland, Portugal, Slovakia, Slovenia, and Spain show a strongly coupled relationship.

The GR also represents a clear disruption in the relationship between MSW and HDI, if we compare the estimated HDI elasticities before and after the GR. The results in Table 2 and Figure 1 allow us to see that this elasticity has clearly decreased in some countries, with Belgium, Denmark, Germany, Greece, Ireland, the Netherlands and Sweden showing the greatest progress towards decoupling after the GR. By contrast, Estonia, Italy, Poland, Portugal and Spain worsened the most. 
There was also an overall reduction in the HDI-MSW estimated elasticities, with Austria, Belgium, Greece, the Netherlands, and the United Kingdom showing the greatest improvement. The only countries that deteriorated are Czechia, Estonia, France, Latvia, Lithuania, Poland, Portugal, Slovakia and Slovenia, increasing their estimated elasticities. The remaining maintained a stable or slightly improved relationship. Therefore, we can observe that not only production but, more broadly, the wellbeing of countries may be becoming decoupled from the generation of waste.

This indicates that while countries that have experienced an increase in decoupling in production have improved or maintained decoupling in their development, countries that have undergone a deterioration in decoupling in production have also maintained or worsened decoupling in their development.

Finally, our results allow us to note that the decoupling between MSW and HDI is less evident than that observed between MSW and GDP, which has been the general trend in European countries during this period.

\section{Discussion}

Our results offer three very interesting insights. First, we observe that the link between waste generation and economic development is heterogeneous across EU countries. The noticeable differences between the GDP elasticities questions the use of the homogeneous panel data approach, as well as revealing the inexistence of an effective shared policy to achieve convergence. Secondly, we can also see that this relationship is quite sensitive to the economic cycle, presenting several breaks. This supports the argument that environmental policy is not a central issue in periods of recession. Additionally, the presence of these breaks confirms the need for relaxing the parameter stability hypothesis in the waste generation/economic growth relationship. Finally, we also see that there is a 
movement towards relative decoupling, although progress is still at an incipient stage and only applies to some EU members.

We also observe that our results offer new evidence about the heterogeneous behavior of EU countries in their transition towards greener economies. In spite of the significant efforts made in order to reduce the differences and facilitate convergence, as CastilloGiménez et al. (2019a) show, such differences are still significant, as can also be seen in Castillo-Giménez et al. (2019b) and in Minelgaitė and Liobikienė (2019). Even worse, we can also observe that the GR has intensified these behavioral differences between European countries, increasing the existing heterogeneity in waste generation.

In this regard, we should note that the recurrence in these environmental policy disparities has led some researchers to divide the EU countries into "leaders, midfielders and laggards" according to the level of implementation of these policies. If we analyze the MSW-GDP elasticities at the end of the sample, we can observe that the countries with negative elasticities are those commonly considered leaders in the literature (Belgium, Denmark, Luxembourg, Netherlands, Sweden and United Kingdom), as Knill et al. (2012) and Melidis and Russel (2020) point out, with the noticeable inclusion of Bulgaria. These countries are distinguished by their ambitious waste prevention plans (European Environment Agency, 2020) with detailed proposals for each sector of the economy and a group of indicators and quantitative objectives that are periodically monitored for compliance. In addition, they have achieved establishing selective collection and recycling as a core element of waste management, severely restricting other alternatives such as dumping or incineration (European Environment Information and Observation Network, 2020). Also significant are the initiatives to raise awareness of environmental issues and the efforts to coordinate the recycled goods market by creating business synergies. 
By contrast, Greece, Poland, Portugal, Slovakia and Slovenia exhibit elasticities greater than 1 , with these countries commonly being classified in the laggard group. This group of countries is defined by a waste treatment sector that is incipient, with limited recycling or selective collection, leaving the largest fraction of urban waste to be landfilled. Furthermore, waste prevention plans may be conditioned in some cases by the need to maintain economic growth in order to converge with the rest of Europe, at the cost of assuming waste increase. The plans of these countries also tend to be less ambitious and lack evaluation or measurable quantitative targets.

The remaining countries, the midfielders, are in a mixed state, with relatively ambitious plans and with a waste treatment system shifting from landfill to recycling or incineration, aiming to achieve the targets imposed by the EU. A similar classification of countries is obtained by Ríos and Picazo-Tadeo (2021) who rank a group of countries according to their waste treatment desirability.

If we consider the HDI as a driver of the MSW, the qualitative conclusions can be maintained as this provides a similar view of the evolution of the countries. The fact that the results for the HDI are higher in absolute value and that decoupling may be more challenging to achieve could be due to two factors. On the one hand, as noted above, there is the bounded construction of the index. On the other hand, following the reasoning of Kalimeris et al. (2020), the HDI increase may require a larger material base than GDP because it takes into account the growth of life expectancy and education.

The picture that emerges from this analysis is quite clear and we can see that the economies with the lowest per capita GDP and HDI levels do not exhibit decoupling. A possible explanation for this result lies in the fact that these countries adopted policies focused on favoring convergence with respect to the rest of the EU countries. As a 
consequence, environmental policies were considered secondary at this time and therefore postponed, as is shown in Burns et al. (2020).

In this regard, we should note that these convergence policies favored the creation of employment and the inherent increase in consumption levels, this being a key factor for understanding the evolution of waste generation, as Khajevand and Tehrani (2019) and Yilmaz (2020) note. By contrast, the most developed countries have had more possibilities to introduce environmental policies, such as recycling or environmental awareness programs, that have proven very effective in reducing urban waste, as can be deduced from Cecere et al. (2014), Gilli et al. (2018) and Cole et al. (2014).

The effect of the GR offers a very clear example of this dual situation. We can see that this economic crisis has significantly altered the relationship between waste and GDP/HDI, as discussed in the results section. Its impact has not been homogenous, being more pronounced in the so-called midfielders and laggards' countries. This can be easily understood if we consider that these countries gave priority to policies of convergence and budgetary stability over environmental policies after the GR. These austerity policies noticeably slowed down the development of necessary environmental regulations and, even worse, led to a loss of ambition in meeting environmental objectives, as Burns et al. (2020) and Burns and Tobin (2020) point out.

Another challenge for public policy is to achieve absolute decoupling considering the heterogeneous nature of Europe. In this regard, our estimated elasticities at the end of the sample mostly show a relative decoupling between waste and GDP and a more modest decoupling between waste and HDI. On this basis, it cannot be firmly concluded that the path towards absolute decoupling, if it is possible, will occur with the traditional development policy mix. According to our results, the convergence policies implemented to date have been unsuccessful in combining economic and environmental development. 
In this regard, we should note that Gardiner and Hayek (2020b) also find evidence of the insufficiency of growth policies to reduce waste generation, especially for lower income countries within the EU. Under these circumstances, the European Union should promote the introduction of new and more powerful environmental policies to reduce waste generation.

Moreover, we consider that waste policies should not only cover the management side, such as promoting recycling, but also amplify their scope by considering other essential factors, mainly consumption patterns, product design and waste/environmental education, as is mentioned in Abbott et al. (2013), Cecere et al. (2014), D'Amato et al. (2016) and Gilli et al. (2018). This policy mix perspective would integrate not only regulations on recycling ratios or material use bans, but encourage a more proactive contribution by generating synergies between companies to move towards industrial ecology, raising awareness among people less inclined to pursue environmental policies and strengthening the role of economic measures such as environmental taxes. Such an environmental policy design would require a more holistic approach in which involving personal motivations may play a crucial role, given the positive effect generated by the desire for social approval that leads people to make visible the fact that they are complying with environmental policies, as Bucciol et al. (2019) note. As a corollary, the modest progress made towards absolute decoupling suggests the necessity of introducing further European policies to establish a genuine green economy.

\section{Conclusions}

This work has analyzed the relationship between environmental degradation and economic developments by studying the link between MSW and two socioeconomic indicators: the standard per capita GDP and the HDI. Our results confirm the existence of 
a clear connection between them, but we have also proved the presence of structural breaks in this relationship. This result demonstrates that waste generation has been quite sensitive to economic shocks such as those resulting from the dot.com crisis (around 2000) and, especially, the GR. Therefore, the inclusion of these events in the model specification has proved to be very helpful for improving the quality of the model estimations and for their better understanding.

The presence of the structural breaks helps us to appropriately estimate the effect of economic developments on waste generation. Once these breaks are accounted for, we can observe that there is relative decoupling between both MSW-GDP and, to a lesser extent, MSW-HDI. We can also see that the Great Recession constituted a severe setback that slowed down much of the progress made until 2007 so far as waste prevention is concerned. In particular, the recovery from the GR (2014-2018) involved an increase in waste generation, especially in those countries with the lowest per capita GDP values.

Our results also offer evidence of the heterogeneity of the environmental behavior of EU countries. The GR even increased the polarization between countries that already had a decoupling relationship before the crisis and maintained it (Denmark, Sweden, and the United Kingdom in the top positions) and those that were in a more modest situation, which in fact deteriorated (Slovakia and Slovenia in the bottom positions).

Consequently, our results show that some countries have achieved the goal of decoupling waste generation and economic growth, but this process is still at a very incipient stage if we analyze the EU as a whole. This suggests that there is still a need to introduce policies at the European level to homogenize results and set more ambitious goals to prevent and reduce waste generation in accordance with international treaties and the commitments made in both the SDGs and the CEAP. 
Finally, as we have mentioned previously, the results are conditioned by the length of the sample. The availability of larger time series of the MSW variables would be recommendable. Then, it seems sensible to carry out new studies once new data are available. In particular, it could be of great interest to relax the restriction that the breaks in the variance are located at the same time as the breaks in the parameter regression, a question that is left for future research. 


\section{References}

Abbott, A., Nandeibam, S., \& O'Shea, L. (2013). Recycling: Social norms and warmglow revisited. Ecological Economics, 90, 10-18.

Andrews, D. W. (1991). Heteroskedasticity and autocorrelation consistent covariance matrix estimation. Econometrica: Journal of the Econometric Society, 817-858.

Aslanidis, N., \& Iranzo, S. (2009). Environment and development: is there a Kuznets curve for CO2 emissions?. Applied Economics, 41(6), 803-810.

Baalbaki, R., \& Marrouch, W. (2020). Is there a garbage Kuznets curve? Evidence from OECD countries". Economics Bulletin, 40(2), 1049-1055.

Bai, J. (1997). Estimating Multiple Breaks One at a Time. Econometric Theory, 13(3), 315-352.

Bai, J., \& Perron, P. (1998). Estimating and Testing Linear Models with Multiple Structural Changes. Econometrica, 66, 47-78.

Bai, J., \& Perron, P. (2003a). Computation and Analysis of Multiple Structural Change Models. Journal of Applied Econometrics, 18, 1-22.

Bai, J., \& Perron, P. (2003b). Critical values for multiple structural change tests. The Econometrics Journal, 6(1), 72-78.

Boubellouta, B., \& Kusch-Brandt, S. (2020). Testing the environmental Kuznets Curve hypothesis for E-waste in the EU28+ 2 countries. Journal of Cleaner Production, 277, 123371.

Boubellouta, B., \& Kusch-Brandt, S. (2021). Relationship between economic growth and mismanaged e-waste: Panel data evidence from 27 EU countries analyzed under the Kuznets curve hypothesis. Waste Management, 120, 85-97.

Breusch, T. S., \& Godfrey, L. G. (1981). A review of recent work on testing for autocorrelation in dynamic simultaneous models. Macroeconomic Analysis, Essays in Macroeconomics and Economics, 1, 63-100.

Bucciol, A., Montinari, N., \& Piovesan, M. (2019). It Wasn't Me! Visibility and Free Riding in Waste Disposal. Ecological Economics, 157, 394-401.

Burns, C., \& Tobin, P. (2020). Crisis, climate change and comitology: Policy dismantling via the backdoor? JCMS: Journal of Common Market Studies, 58(3), 527-544.

Burns, C., Eckersley, P., \& Tobin, P. (2020). EU environmental policy in times of crisis. Journal of European Public Policy, 27(1), 1-19.

Cai, Y., Sam, C. Y., \& Chang, T. (2018). Nexus between clean energy consumption, economic growth and CO2 emissions. Journal of Cleaner Production, 182, 1001-1011. 
Carrion-i-Silvestre, J. L., Kim, D., \& Perron, P. (2009). GLS-based unit root tests with multiple structural breaks under both the null and the alternative hypotheses. Econometric Theory, 1754-1792.

Casini, A., \& Perron, P. (2019). Structural Breaks in Time Series. In Oxford Research Encyclopedia of Economics and Finance. Oxford University Press.

Castillo-Giménez, J., Montañés, A., \& Picazo-Tadeo, A. J. (2019a). Performance and convergence in municipal waste treatment in the European Union. Waste Management, $85,222-231$.

Castillo-Giménez, J., Montañés, A., \& Picazo-Tadeo, A. J. (2019b). Performance in the treatment of municipal waste: Are European Union member states so different? Science of the total environment, 687, 1305-1314.

Cecere, G., Mancinelli, S., \& Mazzanti, M. (2014). Waste prevention and social preferences: the role of intrinsic and extrinsic motivations. Ecological Economics, 107, 163-176.

Chen, J., Wang, P., Cui, L., Huang, S., \& Song, M. (2018). Decomposition and decoupling analysis of CO2 emissions in OECD. Applied energy, 231, 937-950.

Cheng, J., Shi, F., Yi, J., \& Fu, H. (2020). Analysis of the factors that affect the production of municipal solid waste in China. Journal of Cleaner Production, 120808.

Churchill, S. A., Inekwe, J., Ivanovski, K., \& Smyth, R. (2020). Stationarity properties of per capita $\mathrm{CO} 2$ emissions in the OECD in the very long-run: A replication and extension analysis. Energy Economics, 90, 104868.

Cole, M. A., Rayner, A. J., \& Bates, J. M. (1997). The environmental Kuznets curve: an empirical analysis. Environment and Development Economics, 401-416.

Cole, C., Quddus, M., Wheatley, A., Osmani, M., \& Kay, K. (2014). The impact of Local Authorities' interventions on household waste collection: A case study approach using time series modelling. Waste Management, 34(2), 266-272.

D'Amato, A., Mancinelli, S., \& Zoli, M. (2016). Complementarity vs substitutability in waste management behaviors. Ecological Economics, 123, 84-94.

Dickey, D. A., \& Fuller, W. A. (1979). Distribution of the estimators for autoregressive time series with a unit root. Journal of the American statistical association, 74(366a), 427-431.

Durbin, J., \& Watson, G. S. (1950). Testing for serial correlation in least squares regression: I. Biometrika, 37(3/4), 409-428.

Elliott, G., Rothenberg, T. J., \& James, H. (1996). Stock, 1996, “Efficient tests for an autoregressive unit root,". Econometrica, 64(4), 813-836. 
Ercolano, S., Gaeta, G. L. L., Ghinoi, S., \& Silvestri, F. (2018). Kuznets curve in municipal solid waste production: An empirical analysis based on municipal-level panel data from the Lombardy region (Italy). Ecological Indicators, 93, 397-403.

European Environment Agency (2020, March 3). Waste prevention. Country fact sheets. [https://www.eea.europa.eu/themes/waste/waste-prevention/countries].

European Environment Information and Observation Network (2020, March 3). Country profiles on the management of municipal waste [https://www.eionet.europa.eu/etcs/etcwmge/products/country-profiles].

Eurostat (2019). Municipal waste statistics. Eurostat Statistics Explained.

Gardiner, R., \& Hajek, P. (2017). Impact of GDP, capital and employment on waste generation-The case of France, Germany and UK regions. In Proceedings of the 8th International Conference on E-business, Management and Economics (pp. 94-97).

Gardiner, R., \& Hajek, P. (2020a). Effect of GDP, Energy Consumption, and Material Consumption on Waste Generation: The Case of EU-28 Countries. In Eurasian Economic Perspectives (pp. 73-85). Springer, Cham.

Gardiner, R., \& Hajek, P. (2020b). Municipal waste generation, R\&D intensity, and economic growth nexus-A case of EU regions. Waste Management, 114, 124-135.

Gilli, M., Nicolli, F., \& Farinelli, P. (2018). Behavioural attitudes towards waste prevention and recycling. Ecological Economics, 154, 294-305.

Grossman, G. M., \& Krueger, A. B. (1995). Economic growth and the environment. The Quarterly Journal of Economics, 110(2), 353-377.

Gui, S., Zhao, L., \& Zhang, Z. (2019). Does municipal solid waste generation in China support the Environmental Kuznets Curve? New evidence from spatial linkage analysis. Waste Management, 84, 310-319.

Haberl, H., Wiedenhofer, D., Virág, D., Kalt, G., Plank, B., Brockway, P., ... \& Mayer, A. (2020). A systematic review of the evidence on decoupling of GDP, resource use and GHG emissions, part II: synthesizing the insights. Environmental Research Letters, 15(6), 065003.

Holtz-Eakin, D., \& Selden, T. M. (1995). Stoking the fires? CO2 emissions and economic growth. Journal of Public Economics, 57(1), 85-101.

Jebli, M. B., \& Youssef, S. B. (2015). Economic growth, combustible renewables and waste consumption, and CO 2 emissions in North Africa. Environmental Science and Pollution Research, 22(20), 16022-16030.

Johnstone, N., \& Labonne, J. (2004). Generation of household solid waste in OECD countries: an empirical analysis using macroeconomic data. Land Economics, 80(4), 529538. 
Kalimeris, P., Bithas, K., Richardson, C., \& Nijkamp, P. (2020). Hidden linkages between resources and economy: A "Beyond-GDP" approach using alternative welfare indicators. Ecological Economics, 169, 106508.

Khajevand, N., \& Tehrani, R. (2019). Impact of population change and unemployment rate on Philadelphia's waste disposal. Waste Management, 100, 278-286.

Knill, C., Heichel, S., \& Arndt, D. (2012). Really a front-runner, really a Straggler? Of environmental leaders and laggards in the European Union and beyond-A quantitative policy perspective. Energy Policy, 48, 36-45.

Kuznets, S. (1955). Economic growth and income inequality. American Economic Review, 45(1), 1-28.

Madden, B., Florin, N., Mohr, S., \& Giurco, D. (2019). Using the waste Kuznet's curve to explore regional variation in the decoupling of waste generation and socioeconomic indicators. Resources, Conservation and Recycling, 149, 674-686.

Magazzino, C., Mele, M., Schneider, N., \& Sarkodie, S. A. (2021). Waste generation, wealth and GHG emissions from the waste sector: Is Denmark on the path towards circular economy?. Science of the Total Environment, 755, 142510.

Mazzanti, M., \& Zoboli, R. (2008). Waste generation, waste disposal and policy effectiveness: Evidence on decoupling from the European Union. Resources, Conservation and Recycling, 52(10), 1221-1234.

Mazzanti, M., \& Zoboli, R. (2009). Municipal waste Kuznets curves: evidence on socioeconomic drivers and policy effectiveness from the EU. Environmental and Resource Economics, 44(2), 203.

Mazzarano, M., De Jaeger, S., \& Rousseau, S. (2021). Non-constant income elasticities of waste generation. Journal of Cleaner Production, 297, 126611.

Melidis, M., \& Russel, D. J. (2020). Environmental policy implementation during the economic crisis: an analysis of European member state 'leader-laggard' dynamics. Journal of Environmental Policy \& Planning, 22(2), 198-210.

Minelgaite, A., \& Liobikienè, G. (2019). Waste problem in European Union and its influence on waste management behaviours. Science of the Total Environment, 667, 8693.

Montevecchi, F. (2016). Policy mixes to achieve absolute decoupling: a case study of municipal waste management. Sustainability, 8(5), 442.

Namlis, K. G., \& Komilis, D. (2019). Influence of four socioeconomic indices and the impact of economic crisis on solid waste generation in Europe. Waste Management, 89, 190-200.

Perron, P. (1989). The great crash, the oil price shock, and the unit root hypothesis. Econometrica: Journal of the Econometric Society, 1361-1401. 
Perron, P., Yamamoto, Y., \& Zhou, J. (2020). Testing jointly for structural changes in the error variance and coefficients of a linear regression model. Quantitative Economics, 11(3), 1019-1057.

Qu, Z., \& Perron, P. (2007). Estimating and testing structural changes in multivariate regressions. Econometrica, 75(2), 459-502.

Ríos, A. M., \& Picazo-Tadeo, A. J. (2021). Measuring environmental performance in the treatment of municipal solid waste: The case of the European Union-28. Ecological Indicators, 123, 107328.

Sanyé-Mengual, E., Secchi, M., Corrado, S., Beylot, A., \& Sala, S. (2019). Assessing the decoupling of economic growth from environmental impacts in the European Union: A consumption-based approach. Journal of cleaner production, 236, 117535.

Schwarz, G. (1978). Estimating the dimension of a model. The annals of statistics, 6(2), 461-464.

Shuai, C., Chen, X., Wu, Y., Zhang, Y., \& Tan, Y. (2019). A three-step strategy for decoupling economic growth from carbon emission: empirical evidences from 133 countries. Science of the Total Environment, 646, 524-543.

Tao, S., Zheng, T., \& Lianjun, T. (2008). An empirical test of the environmental Kuznets curve in China: a panel cointegration approach. China Economic Review, 19(3), 381-392.

Vadén, T., Lähde, V., Majava, A., Järvensivu, P., Toivanen, T., Hakala, E., \& Eronen, J. T. (2020). Decoupling for ecological sustainability: A categorisation and review of research literature. Environmental Science \& Policy, 112, 236-244.

Vujić, G., Gonzalez-Roof, A., Stanisavljević, N., \& Ragossnig, A. M. (2015). Municipal solid waste development phases: Evidence from EU27. Waste Management \& Research, 33(12), 1112-1120.

Wang, Y. C. (2013). Functional sensitivity of testing the environmental Kuznets curve hypothesis. Resource and Energy Economics, 35(4), 451-466.

Wang, Q., \& Wang, S. (2019). Decoupling economic growth from carbon emissions growth in the United States: the role of research and development. Journal of Cleaner Production, 234, 702-713.

Yilanci, V., Gorus, M. S., \& Aydin, M. (2019). Are shocks to ecological footprint in OECD countries permanent or temporary? Journal of Cleaner Production, 212, 270-301.

Y1lmaz, F. (2020). Is there a waste Kuznets curve for OECD? Some evidence from panel analysis. Environmental Science and Pollution Research, 1-15.

Zhao, X., Zhang, X., Li, N., Shao, S., \& Geng, Y. (2017). Decoupling economic growth from carbon dioxide emissions in China: a sectoral factor decomposition analysis. Journal of Cleaner Production, 142, 3500-3516. 
Table 1. Testing for breaks and estimation of the equation (GDP and MSW)

\begin{tabular}{|c|c|c|c|c|c|c|c|c|c|c|c|c|c|c|c|c|}
\hline & UD $_{\text {Max }}$ & $\mathrm{WD}_{\max }$ & $\alpha_{1}$ & $\beta_{1}$ & $\mathrm{~TB}_{1}$ & $\alpha_{2}$ & $\beta_{2}$ & $\mathrm{~TB}_{2}$ & $\alpha_{3}$ & $\beta_{3}$ & $\mathrm{~TB}_{3}$ & $\alpha_{4}$ & $\beta_{4}$ & R2 & $\overline{\mathrm{DDW}}$ & $\overline{\mathrm{LM} 1}$ \\
\hline \multirow[t]{2}{*}{ EU27 } & 334 & 515 & -6.30 & 0.56 & 2002 & -4.68 & 0.40 & 2009 & -6.78 & 0.60 & 2013 & -4.55 & 0.38 & 0.90 & 1.9 & 0.0 \\
\hline & & & 0.78 & 0.08 & & 0.25 & 0.02 & & 5.46 & 0.54 & & 0.34 & 0.03 & & & \\
\hline \multirow[t]{2}{*}{ Austria } & 52 & 64 & -16.00 & 1.49 & 2003 & -6.01 & 0.52 & 2009 & -4.38 & 0.36 & & & & 0.87 & 1.7 & 0.1 \\
\hline & & & 3.3 & 0.32 & & 0.68 & 0.06 & & 0.5 & 0.05 & & & & & & \\
\hline \multirow[t]{2}{*}{ Belgium } & 432 & 432 & -4.32 & 0.35 & 2008 & 15.54 & -1.57 & 2012 & 8.47 & -0.89 & & & & 0.96 & 2.7 & $3.9 *$ \\
\hline & & & 0.34 & 0.03 & & 4.32 & 0.41 & & 2.25 & 0.21 & & & & & & \\
\hline \multirow[t]{2}{*}{ Bulgaria } & 106 & 129 & 0.71 & -0.15 & 2011 & 1.66 & -0.29 & & & & & & & 0.91 & 1.6 & 0.0 \\
\hline & & & 0.6 & 0.07 & & 1.42 & 0.16 & & & & & & & & & \\
\hline \multirow[t]{2}{*}{ Cyprus(b) } & 59 & 84 & -3.20 & 0.28 & 2000 & -5.3 & 0.49 & 2007 & -9.46 & 0.9 & 2013 & -3.52 & 0.31 & 0.96 & 2.3 & 0.7 \\
\hline & & & 0.62 & 0.06 & & 0.38 & 0.04 & & 0.6 & 0.06 & & 1.27 & 0.13 & & & \\
\hline \multirow[t]{2}{*}{ Czechia } & 172 & 257 & -12.58 & 1.23 & 2000 & -4.32 & 0.32 & 2008 & -7.6 & 0.67 & & & & 0.90 & 2.3 & 0.5 \\
\hline & & & 2.16 & 0.1 & & 0.31 & 0.03 & & 1.1 & 0.11 & & & & & & \\
\hline \multirow[t]{2}{*}{ Denmark } & 110 & 143 & -16.05 & 1.47 & 2006 & 0.57 & -0.07 & & & & & & & 0.94 & 2.5 & 2.6 \\
\hline & & & 1.8 & 0.17 & & 2.69 & 0.25 & & & & & & & & & \\
\hline \multirow[t]{2}{*}{ Estonia } & 333 & 407 & -1.63 & 0.08 & 2008 & 7.25 & -0.9 & 2013 & -9.56 & 0.9 & & & & 0.87 & 2.6 & 2.8 \\
\hline & & & 0.41 & 0.04 & & 2.5 & 0.27 & & 0.33 & 0.03 & & & & & & \\
\hline \multirow[t]{2}{*}{ Finland } & 113 & 125 & -10.09 & 0.91 & 2000 & -8.84 & 0.78 & & & & & & & 0.89 & 1.5 & 0.2 \\
\hline & & & 0.61 & 0.06 & & 1.35 & 0.13 & & & & & & & & & \\
\hline \multirow[t]{2}{*}{ France } & 94 & 144 & -6.21 & 0.54 & 2011 & -3.00 & 0.23 & & & & & & & 0.89 & 1.8 & 0.1 \\
\hline & & & 0.43 & 0.04 & & 1.46 & 0.14 & & & & & & & & & \\
\hline \multirow[t]{2}{*}{ Germany } & 77 & 119 & -0.21 & -0.02 & 2002 & 9.87 & -1.01 & 2006 & -5.25 & 0.46 & & & & 0.85 & 1.4 & 0.9 \\
\hline & & & 1.73 & 0.17 & & 3.83 & 0.37 & & 1.02 & 0.1 & & & & & & \\
\hline \multirow[t]{2}{*}{ Greece(b) } & 515 & 629 & -23.11 & 2.28 & 1998 & -5.25 & 0.45 & 2009 & -5.53 & 0.49 & 2013 & -14.85 & 1.45 & 0.99 & 1.9 & 0.0 \\
\hline & & & 3.67 & 0.38 & & 0.46 & 0.05 & & 0.39 & 0.04 & & 2.64 & 0.27 & & & \\
\hline \multirow[t]{2}{*}{ Ireland(b) } & 443 & 680 & -4.66 & 0.40 & 2000 & -6.59 & 0.60 & 2004 & -19.6 & 1.82 & 2011 & -0.64 & 0.01 & 0.98 & 2.6 & 1.4 \\
\hline & & & 0.13 & 0.01 & & 1.15 & 0.11 & & 2.65 & 0.25 & & 0.37 & 0.03 & & & \\
\hline \multirow[t]{2}{*}{ Italy } & 56 & 86 & -9.80 & 0.89 & 1998 & -9.26 & 0.84 & 2003 & -5.23 & 0.45 & 2011 & -5.47 & 0.47 & 0.98 & 2.5 & 1.6 \\
\hline & & & 0.8 & 0.08 & & 1.14 & 0.11 & & 2.03 & 0.2 & & 2.22 & 0.22 & & & \\
\hline \multirow[t]{2}{*}{ Latvia } & 314 & 384 & -4.35 & 0.36 & 2014 & -1.50 & 0.06 & & & & & & & 0.89 & 1.6 & 0.5 \\
\hline & & & 0.38 & 0.04 & & 0.68 & 0.07 & & & & & & & & & \\
\hline Lithuania & 106 & 129 & -3.07 & 0.26 & 1998 & -7.30 & 0.73 & 2002 & -3.85 & 0.32 & & & & 0.89 & 1.9 & 0.0 \\
\hline & & & 1.6 & 0.19 & & 0.35 & 0.04 & & 0.33 & 0.04 & & & & & & \\
\hline Luxembourg & 365 & 365 & -7.52 & 0.64 & 1999 & -4.60 & 0.37 & 2012 & 2.78 & -0.29 & & & & 0.95 & 1.5 & 1.6 \\
\hline & & & 0.37 & 0.03 & & 0.77 & 0.07 & & 2.46 & 0.22 & & & & & & \\
\hline Netherlands & 337 & 519 & -3.00 & 0.24 & 2011 & 5.27 & -0.56 & & & & & & & 0.87 & 1.3 & 2.1 \\
\hline & & & 0.87 & 0.08 & & 1.84 & 0.17 & & & & & & & & & \\
\hline Poland(a) & 64 & 98 & -4.65 & 0.40 & 2000 & 8.82 & -1.15 & 2004 & -0.08 & -0.12 & 2013 & -11.79 & 1.13 & 0.93 & 2.2 & 0.5 \\
\hline & & & 0.72 & 0.08 & & 2.39 & 0.27 & & 0.75 & 0.08 & & 1.10 & 0.12 & & & \\
\hline Portugal & 102 & 125 & -14.70 & 1.44 & 2000 & -10.93 & 1.04 & 2007 & -9.35 & 0.89 & 2011 & -10.78 & 1.03 & 0.98 & 2.8 & $3.8 *$ \\
\hline & & & 0.43 & 0.05 & & 1.21 & 0.12 & & 9.85 & 1.01 & & 0.61 & 0.06 & & & \\
\hline Slovakia & 421 & 515 & 7.02 & -0.94 & 2001 & -4.71 & 0.37 & 2014 & -26.64 & 2.67 & & & & 0.97 & 1.8 & 0.3 \\
\hline & & & 0.99 & 0.11 & & 0.62 & 0.06 & & 0.73 & 0.08 & & & & & & \\
\hline Slovenia & 240 & 369 & 7.69 & -0.87 & 2001 & -11.16 & 1.07 & 2010 & -13.98 & 1.34 & & & & 0.90 & 1.5 & 1.1 \\
\hline & & & 1.83 & 0.19 & & 1.62 & 0.17 & & 3.22 & 0.33 & & & & & & \\
\hline Spain & 627 & 966 & -11.02 & 1.06 & 2003 & 4.39 & -0.50 & 2007 & -19.68 & 1.89 & 2013 & -6.35 & 0.55 & 0.98 & 2.0 & 0.0 \\
\hline & & & 0.98 & 0.10 & & 1.20 & 0.12 & & 2.08 & 0.20 & & 0.23 & 0.02 & & & \\
\hline Sweden & 129 & 139 & -15.62 & 1.43 & 1998 & -7.66 & 0.66 & 2009 & 0.49 & -0.12 & & & & 0.94 & 1.9 & 0.0 \\
\hline & & & 1.02 & 0.1 & & 0.87 & 0.08 & & 1.86 & 0.17 & & & & & & \\
\hline U. Kingdom & 597 & 730 & -10.15 & 0.94 & 2002 & 8.21 & -0.85 & 2008 & 35.26 & -3.49 & 2012 & 5.27 & -0.58 & 0.97 & 1.9 & 0.0 \\
\hline & & & 0.3 & 0.03 & & 3.64 & 0.35 & & 3.56 & 0.34 & & 2.57 & 0.25 & & & \\
\hline
\end{tabular}

This table presents the results of the estimation of model (2), using HDI instead of per capita GDP, with TBj (i=1,2,3) being the estimated periods when the break appears. The number of breaks has been selected by using the sequential procedure described in Bai and Perron (1998). UD $\max$ and WD max test the no structural break null hypothesis, which is rejected in all the reported cases when using the appropriate critical values. Robust standard deviations are presented below the estimated parameters. DW is the statistic proposed in Durbin and Watson (1950), whilst LM1 is the one proposed in Breusch and Godfrey (1981) for testing for $1^{\text {st }}$ order autocorrelation.

(a)Structural breaks selected by BIC. (b) Last observation 2017. * means rejection of the null hypothesis of no first order autocorrelation for a $10 \%$ significance level. 
Table 2. Testing for breaks and estimation of the equation (HDI and MSW)

\begin{tabular}{|c|c|c|c|c|c|c|c|c|c|c|c|c|c|c|c|c|}
\hline & $U_{\text {Max }}$ & $\mathrm{WD}_{\max }$ & $\alpha_{1}$ & $\beta_{1}$ & $\mathrm{~TB}_{1}$ & $\alpha_{2}$ & $\beta_{2}$ & $\mathrm{~TB}_{2}$ & $\alpha_{3}$ & $\beta_{3}$ & $\mathrm{~TB}_{3}$ & $\alpha_{4}$ & $\beta_{4}$ & $\mathrm{R} 2$ & $\overline{\mathrm{DW}}$ & LM1 \\
\hline \multirow[t]{2}{*}{ Austria } & 25 & 39 & -59.91 & 8.82 & 2000 & 22.67 & -3.44 & 2005 & 6.56 & -1.04 & & & & 0.86 & 1.8 & 0.2 \\
\hline & & & 17.39 & 2.59 & & 5.21 & 0.77 & & 1.76 & 0.26 & & & & & & \\
\hline \multirow[t]{2}{*}{ Belgium } & 347 & 535 & -0.81 & -0.16 & 1998 & -0.55 & 1.52 & 2008 & -1.46 & -6.56 & & & & 0.96 & 2.5 & 1.9 \\
\hline & & & 0.06 & 0.38 & & 0.03 & 0.22 & & 0.06 & 0.57 & & & & & & \\
\hline \multirow[t]{2}{*}{ Bulgaria } & 66 & 102 & -0.76 & -0.78 & 2010 & -1.60 & -3.46 & & & & & & & 0.93 & 1.6 & 0.0 \\
\hline & & & 0.12 & 0.40 & & 0.26 & 1.18 & & & & & & & & & \\
\hline \multirow[t]{2}{*}{ Cyprus(b) } & 307 & 375 & 0.07 & 2.34 & 2007 & 0.76 & 6.89 & 2011 & -0.35 & 0.72 & & & & 0.89 & 2.5 & 1.1 \\
\hline & & & 0.02 & 0.08 & & 0.70 & 4.28 & & 0.21 & 1.53 & & & & & & \\
\hline \multirow[t]{2}{*}{ Czechia } & 116 & 120 & -0.68 & 1.89 & 2000 & -0.91 & 1.82 & 2008 & -1.43 & -1.90 & 2013 & 0.10 & 9.89 & 0.92 & 2.6 & 2.0 \\
\hline & & & 0.12 & 0.45 & & 0.04 & 0.20 & & 0.06 & 0.39 & & 0.11 & 0.86 & & & \\
\hline \multirow[t]{2}{*}{ Denmark } & 44 & 68 & 0.00 & 3.16 & 2002 & 0.55 & 8.45 & 2006 & 0.07 & 3.07 & 2011 & -0.36 & -1.42 & 0.95 & 2.5 & 2.9 \\
\hline & & & 0.11 & 0.79 & & 0.06 & 0.55 & & 0.09 & 1.05 & & 0.13 & 1.66 & & & \\
\hline \multirow[t]{2}{*}{ Estonia } & 144 & 176 & -0.78 & 0.47 & 2008 & -2.01 & -5.06 & 2013 & -0.07 & 6.74 & & & & 0.87 & 2.6 & 2.4 \\
\hline & & & 0.06 & 0.27 & & 0.24 & 1.46 & & 0.17 & 1.25 & & & & & & \\
\hline \multirow[t]{2}{*}{ Finland } & 103 & 103 & -0.02 & 4.33 & 2000 & -0.54 & 1.66 & & & & & & & 0.82 & 1.5 & 0.4 \\
\hline & & & 0.06 & 0.34 & & 0.04 & 0.33 & & & & & & & & & \\
\hline \multirow[t]{2}{*}{ France } & 213 & 328 & -0.22 & 2.64 & 2005 & -0.85 & -1.66 & 2013 & -0.21 & 3.75 & & & & 0.86 & 1.5 & 1.1 \\
\hline & & & 0.09 & 0.49 & & 0.06 & 0.42 & & 0.11 & 0.92 & & & & & & \\
\hline \multirow[t]{2}{*}{ Germany(a) } & 171 & 264 & -0.45 & -0.02 & 2002 & -0.85 & -2.88 & 2006 & -0.13 & 4.56 & 2014 & -0.75 & -4.31 & 0.93 & 1.9 & 0.2 \\
\hline & & & 0.05 & 0.34 & & 0.05 & 0.46 & & 0.03 & 0.34 & & 0.10 & 1.47 & & & \\
\hline \multirow[t]{2}{*}{ Greece(b) } & 24 & 37 & 1.08 & 8.44 & 1999 & -0.62 & 1.15 & 2005 & -0.39 & 2.48 & 2009 & -0.85 & -1.00 & 0.97 & 1.7 & 0.1 \\
\hline & & & 0.38 & 1.56 & & 0.01 & 0.03 & & 0.14 & 0.88 & & 0.21 & 1.42 & & & \\
\hline \multirow[t]{2}{*}{ Hungary(a) } & 155 & 238 & -0.28 & 1.60 & 1999 & -0.60 & 0.80 & 2006 & -2.50 & -8.39 & 2010 & -1.14 & -0.98 & 0.97 & 2.3 & 0.9 \\
\hline & & & 0.24 & 0.85 & & 0.02 & 0.10 & & 0.35 & 1.77 & & 0.15 & 0.82 & & & \\
\hline \multirow[t]{2}{*}{ Ireland(b) } & 38 & 59 & -0.25 & 1.78 & 2000 & -0.04 & 2.17 & 2008 & -1.02 & -4.90 & 2013 & -0.45 & 1.35 & 0.96 & 2.8 & $3.8^{*}$ \\
\hline & & & 0.06 & 0.27 & & 0.11 & 0.82 & & 0.10 & 1.00 & & 0.03 & 0.38 & & & \\
\hline \multirow[t]{2}{*}{ Italy } & 264 & 323 & -0.39 & 1.79 & 1998 & -0.25 & 2.32 & 2005 & -1.13 & -3.77 & 2011 & -0.69 & 0.07 & 0.98 & 2.6 & 1.9 \\
\hline & & & 0.02 & 0.14 & & 0.02 & 0.12 & & 0.10 & 0.73 & & 0.16 & 1.26 & & & \\
\hline Latvia & 113 & 174 & -1.35 & 0.02 & 2000 & -0.83 & 1.19 & 2014 & -0.80 & 0.61 & & & & 0.92 & 2.1 & 0.1 \\
\hline & & & 0.18 & 0.48 & & 0.09 & 0.40 & & 0.11 & 0.67 & & & & & & \\
\hline Lithuania & 73 & 89 & -0.44 & 1.27 & 1998 & -0.13 & 3.12 & 2002 & -0.47 & 2.20 & & & & 0.86 & 1.8 & 0.0 \\
\hline & & & 0.31 & 0.95 & & 0.09 & 0.30 & & 0.04 & 0.24 & & & & & & \\
\hline Luxembourg & 276 & 337 & -0.14 & 1.94 & 2011 & -0.68 & -1.97 & & & & & & & 0.91 & 2.2 & 0.2 \\
\hline & & & 0.02 & 0.16 & & 0.09 & 0.93 & & & & & & & & & \\
\hline Netherlands & 191 & 295 & 0.54 & 7.73 & 1999 & -0.48 & 0.28 & 2008 & -0.81 & -2.82 & 2012 & -0.86 & -2.90 & 0.97 & 2.8 & $3.5^{*}$ \\
\hline & & & 0.18 & 1.29 & & 0.02 & 0.17 & & 0.11 & 1.20 & & 0.02 & 0.28 & & & \\
\hline Poland(a) & 617 & 950 & -0.73 & 1.68 & 2000 & -3.03 & -7.67 & 2004 & -1.35 & -1.04 & 2013 & 0.07 & 8.65 & 0.95 & 1.9 & 0.0 \\
\hline & & & 0.10 & 0.38 & & 0.22 & 0.95 & & 0.11 & 0.58 & & 0.03 & 0.18 & & & \\
\hline Portugal & 107 & 164 & 0.71 & 6.40 & 1998 & -0.44 & 1.51 & 2007 & -2.03 & -6.80 & 2013 & 0.85 & 9.52 & 0.97 & 1.9 & 0.0 \\
\hline & & & 0.08 & 0.31 & & 0.11 & 0.51 & & 0.19 & 0.97 & & 0.26 & 1.51 & & & \\
\hline Romania & 136 & 182 & -0.55 & 1.60 & 2009 & -1.36 & -0.09 & & & & & & & 0.85 & 2.0 & 0.0 \\
\hline & & & 0.09 & 0.33 & & 0.68 & 3.19 & & & & & & & & & \\
\hline Slovakia & 3915 & 4758 & -3.90 & -9.32 & 2001 & -0.95 & 1.42 & 2007 & -1.20 & -0.16 & 2014 & 2.89 & 24.44 & 0.98 & 2.3 & 0.5 \\
\hline & & & 0.34 & 1.23 & & 0.13 & 0.57 & & 0.12 & 0.64 & & 0.03 & 0.21 & & & \\
\hline Slovenia & 113 & 175 & -1.28 & -3.20 & 2001 & 0.11 & 5.74 & 2010 & 1.06 & 15.68 & 2014 & -0.27 & 4.44 & 0.93 & 1.4 & 1.8 \\
\hline & & & 0.13 & 0.59 & & 0.18 & 1.21 & & 0.06 & 0.47 & & 0.07 & 0.65 & & & \\
\hline Spain & 573 & 883 & 0.94 & 7.30 & 1999 & -1.35 & -4.91 & 2005 & -1.87 & -8.26 & 2011 & -0.59 & 1.46 & 0.99 & 2.4 & 0.9 \\
\hline & & & 4.66 & 0.70 & & 3.74 & 0.56 & & 2.49 & 0.37 & & 1.88 & 0.28 & & & \\
\hline Sweden(a) & 198 & 242 & -0.42 & 3.47 & 1998 & -0.14 & 6.38 & 2003 & -0.07 & 6.33 & 2009 & -0.81 & -0.20 & 0.95 & 2.5 & $3.2 *$ \\
\hline & & & 0.03 & 0.24 & & 0.10 & 0.95 & & 0.17 & 1.63 & & 0.03 & 0.38 & & & \\
\hline U. Kingdom & 450 & 693 & 0.04 & 4.14 & 2003 & -1.52 & -8.39 & 2010 & -0.81 & -0.86 & & & & 0.98 & 1.7 & 0.1 \\
\hline & & & 0.06 & 0.32 & & 0.05 & 0.71 & & 0.07 & 0.66 & & & & & & \\
\hline
\end{tabular}

This table presents the results of the estimation of model (2), using HDI instead of per capita GDP, with TBj (i=1,2,3) being the estimated periods when the break appears. The number of breaks has been selected by using the sequential procedure described in Bai and Perron (1998). UD ${ }_{\max }$ and $\mathrm{WD}_{\max }$ test the no structural break null hypothesis, which is rejected in all the reported cases when using the appropriate critical values. Robust standard deviations are presented below the estimated parameters. DW is the statistic proposed in Durbin and Watson (1950), whilst LM1 is the one proposed in Breusch and Godfrey (1981) for testing for $1^{\text {st }}$ order autocorrelation.

(a)Structural breaks selected by BIC. (b) Last observation 2017. * means rejection of the null hypothesis of no first order autocorrelation for a $10 \%$ significance level. 
Figure 1. Elasticities between MSW and GDP/HDI

Figure 1.A MSW/GDP estimated elasticities in 1995

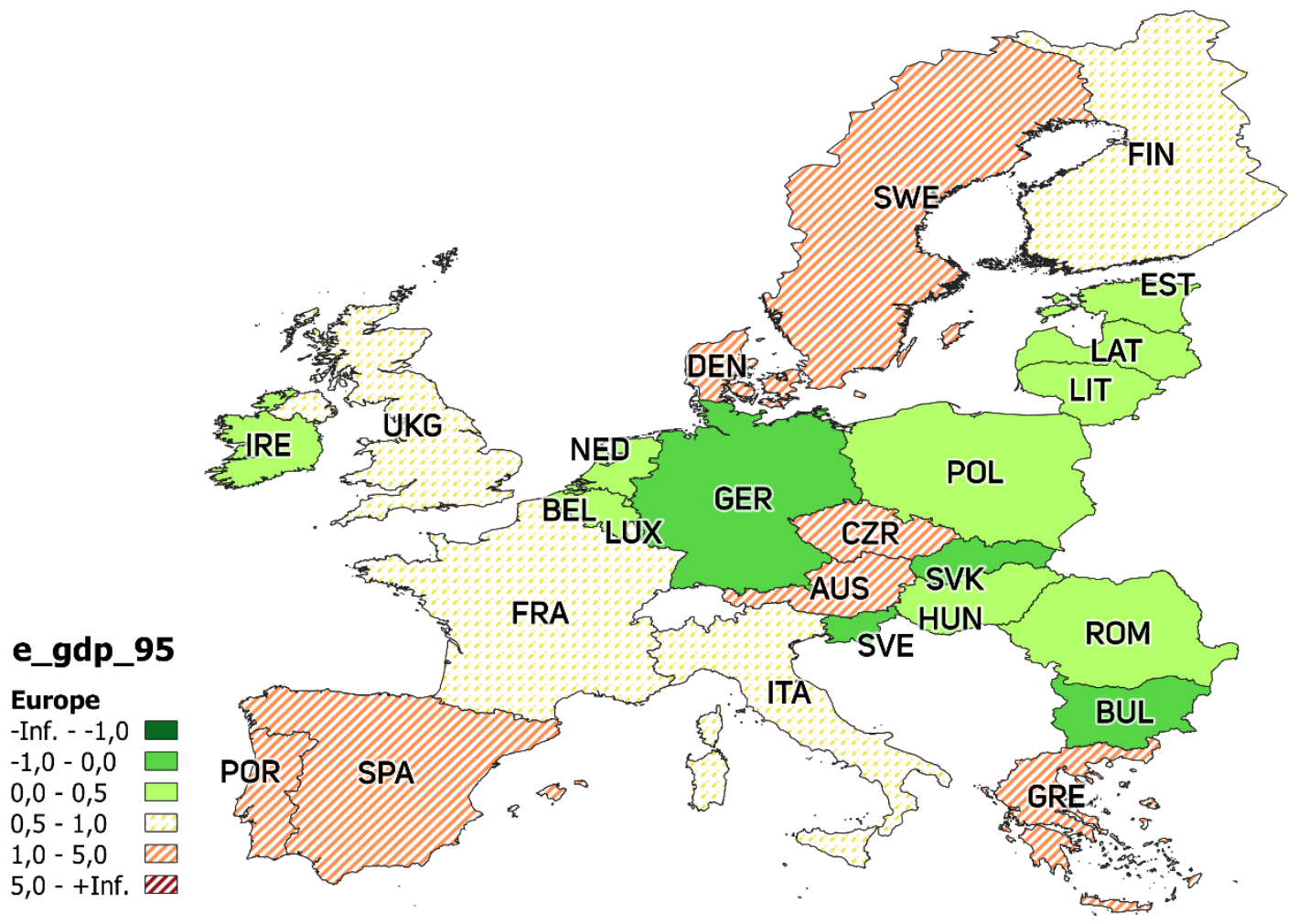

Figure 1.B HDI/GDP estimated elasticities in 1995

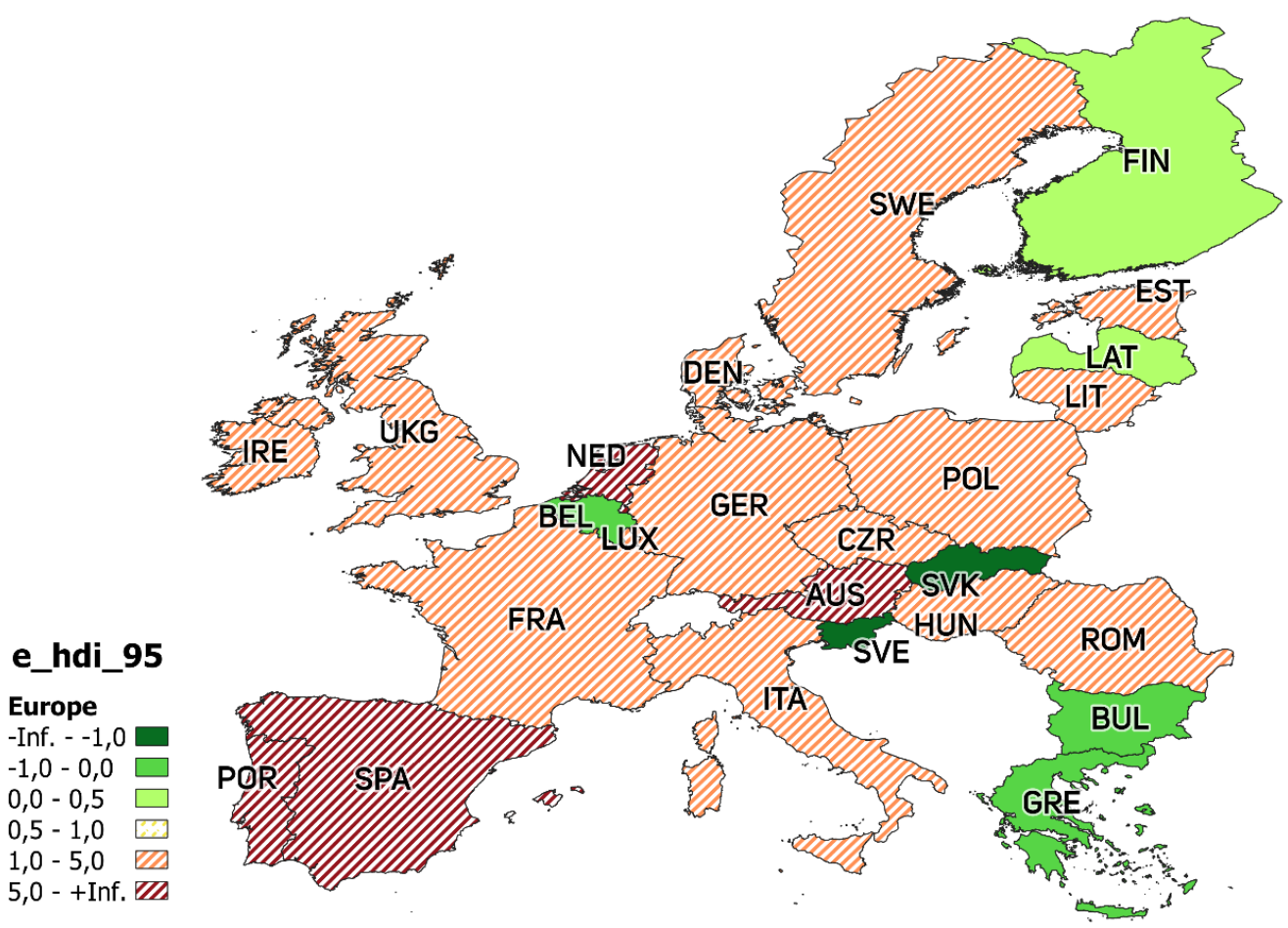




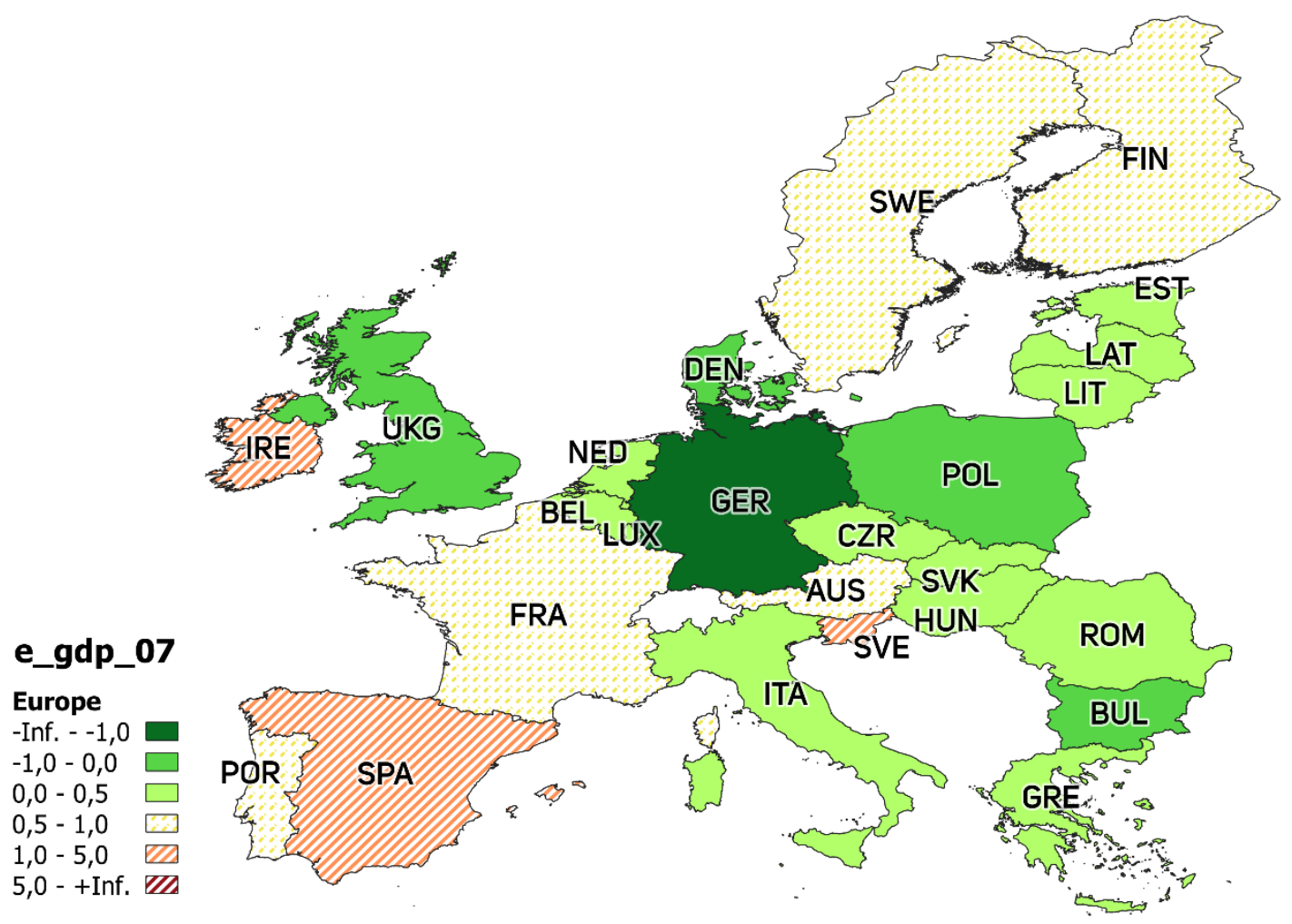

Figure 1.D HDI/GDP estimated elasticities in 2007
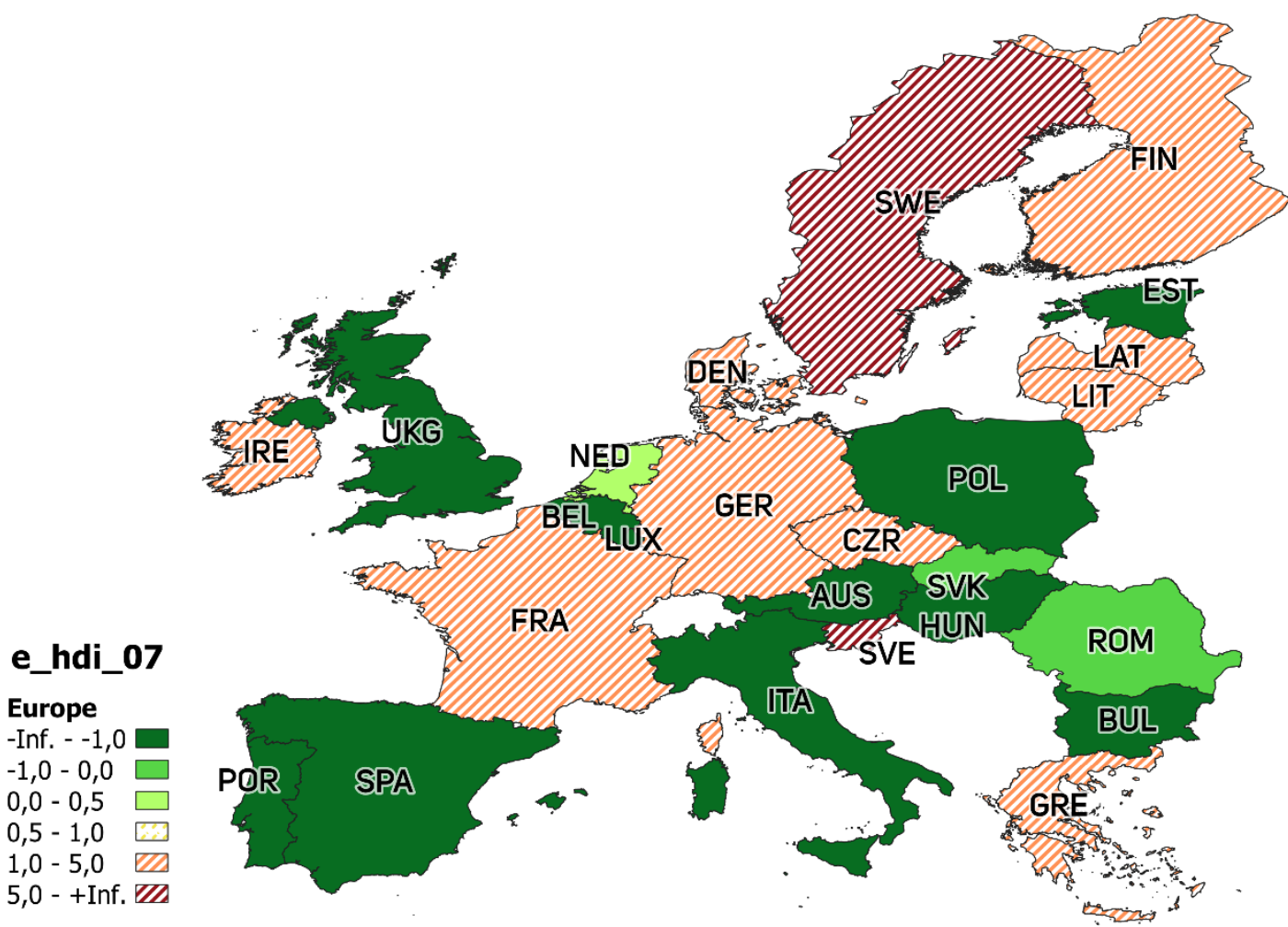


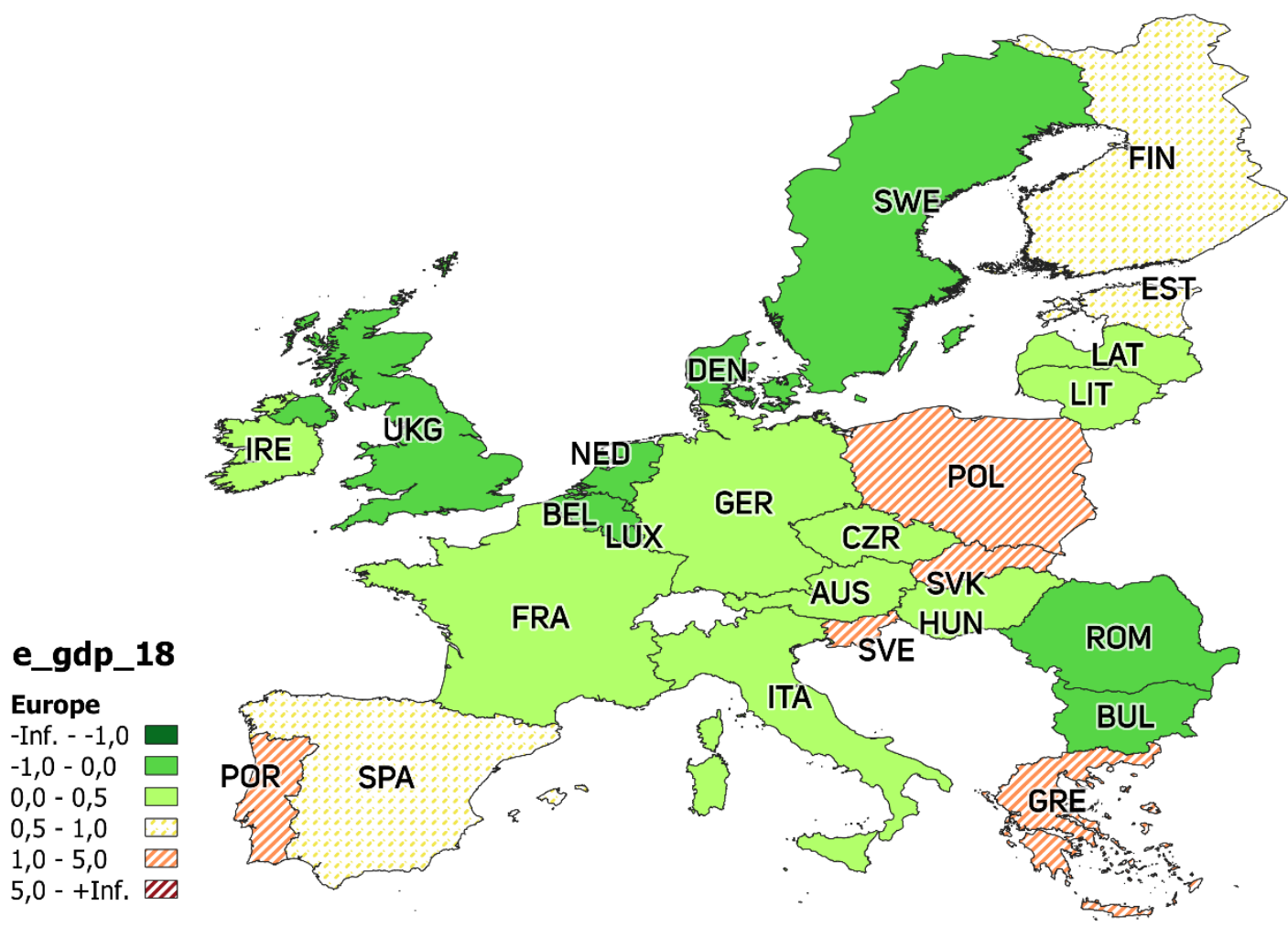

Figure 1.F HDI/GDP estimated elasticities in 2018
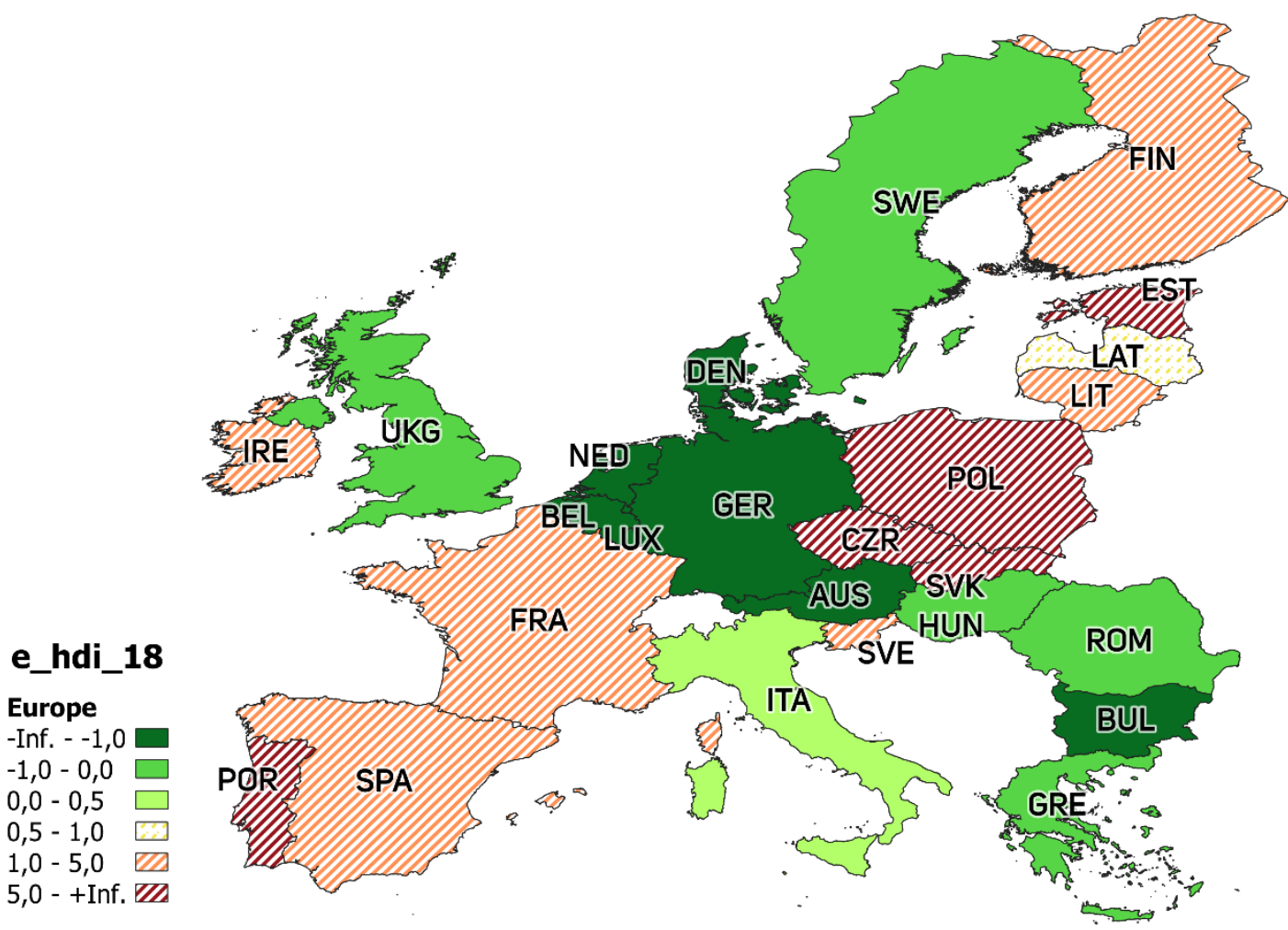


\section{Appendix}

Table A1. Descriptive analysis

\begin{tabular}{|c|c|c|c|c|c|c|c|c|c|c|c|c|c|c|c|c|c|c|c|c|c|}
\hline & \multicolumn{7}{|c|}{ MSW (thousands of Kg) } & \multicolumn{7}{|c|}{ GDP (euros) } & \multicolumn{7}{|c|}{ HDI (between 0 and 1) } \\
\hline & 1995 & 2018 & $95-18$ & $95-07$ & $07-18$ & $07-14$ & $14-18$ & 1995 & 2018 & $95-18$ & $95-07$ & $07-18$ & $07-14$ & $14-18$ & 1995 & 2018 & $95-18$ & $95-07$ & $07-18$ & $07-14$ & $14-18$ \\
\hline EU27 & 0.465 & 0.492 & $0.3 \%$ & $0.9 \%$ & $-0.5 \%$ & $-1.2 \%$ & $0.8 \%$ & 19,707 & 27,681 & $1.5 \%$ & $2.2 \%$ & $0.7 \%$ & $0.0 \%$ & $2.1 \%$ & 0.780 & 0.890 & $0.6 \%$ & $0.8 \%$ & $0.4 \%$ & $0.4 \%$ & $0.4 \%$ \\
\hline Austria & 0.438 & 0.580 & $1.2 \%$ & $2.6 \%$ & $-0.3 \%$ & $-0.7 \%$ & $0.5 \%$ & 27,604 & 37,873 & $1.4 \%$ & $2.2 \%$ & $0.5 \%$ & $0.1 \%$ & $1.1 \%$ & 0.817 & 0.914 & $0.5 \%$ & $0.6 \%$ & $0.3 \%$ & $0.4 \%$ & $0.3 \%$ \\
\hline Belgium & 0.455 & 0.412 & $-0.4 \%$ & $0.7 \%$ & $-1.7 \%$ & $-2.1 \%$ & $-0.8 \%$ & 26,267 & 35,686 & $1.3 \%$ & $2.1 \%$ & $0.5 \%$ & $0.0 \%$ & $1.3 \%$ & 0.851 & 0.919 & $0.3 \%$ & $0.5 \%$ & $0.2 \%$ & $0.2 \%$ & $0.2 \%$ \\
\hline Cyprus & 0.600 & 0.640 & $0.3 \%$ & $1.4 \%$ & $-1.1 \%$ & $-2.2 \%$ & $1.6 \%$ & 17,643 & 23,927 & $1.3 \%$ & $2.9 \%$ & $-0.6 \%$ & $-2.9 \%$ & $7.5 \%$ & 0.783 & 0.873 & $0.5 \%$ & $0.6 \%$ & $0.3 \%$ & $0.2 \%$ & $0.9 \%$ \\
\hline Czechia & 0.302 & 0.352 & $0.7 \%$ & $-0.2 \%$ & $1.6 \%$ & $0.7 \%$ & $3.2 \%$ & 10,163 & 17,651 & $2.4 \%$ & & $1.3 \%$ & $0.1 \%$ & $3.5 \%$ & 0.753 & 0.891 & $0.7 \%$ & $0 \%$ & $4 \%$ & $0.5 \%$ & $0.3 \%$ \\
\hline Denmark & 0.522 & 0.767 & $1.7 \%$ & $3.5 \%$ & $-0.3 \%$ & $-0.3 \%$ & $-0.2 \%$ & 37,222 & 48,372 & $1.1 \%$ & $1.8 \%$ & $0.4 \%$ & $-0.4 \%$ & $1.8 \%$ & 0.831 & 0.930 & $0.5 \%$ & $0.7 \%$ & $0.3 \%$ & $0.4 \%$ & $0.1 \%$ \\
\hline Estonia & 0.368 & 0.406 & $0.4 \%$ & $1.7 \%$ & $-0.9 \%$ & $-3.2 \%$ & $3.2 \%$ & 5,398 & 15,086 & $4.6 \%$ & $7.8 \%$ & $1.2 \%$ & $-0.2 \%$ & $3.7 \%$ & 0.724 & 0.882 & $0.9 \%$ & $1.2 \%$ & $0.5 \%$ & $0.4 \%$ & $0.5 \%$ \\
\hline Finland & 0.414 & 0.552 & $1.3 \%$ & $1.7 \%$ & $0.8 \%$ & $-0.7 \%$ & $3.4 \%$ & 24,130 & 36,909 & $1.9 \%$ & $3.7 \%$ & $-0.1 \%$ & $-1.1 \%$ & $1.7 \%$ & 0.816 & 0.925 & $0.5 \%$ & $0.8 \%$ & $0.2 \%$ & $0.3 \%$ & $0.2 \%$ \\
\hline France & 0.476 & 0.527 & $0.4 \%$ & $1.1 \%$ & $-0.3 \%$ & $-0.7 \%$ & $0.4 \%$ & 25,707 & 33,002 & $1.1 \%$ & $1.7 \%$ & $0.4 \%$ & $-0.1 \%$ & $1.3 \%$ & 0.825 & 0.891 & $0.3 \%$ & $0.4 \%$ & $0.2 \%$ & $0.3 \%$ & $0.1 \%$ \\
\hline Germany & 0.624 & 0.616 & $-0.1 \%$ & $-0.6 \%$ & $0.5 \%$ & $1.2 \%$ & $-0.7 \%$ & 26,308 & 35,907 & $1.4 \%$ & $1.5 \%$ & $1.2 \%$ & $1.1 \%$ & $1.4 \%$ & 0.834 & 0.939 & $0.5 \%$ & $0.8 \%$ & $0.2 \%$ & $0.2 \%$ & $0.2 \%$ \\
\hline Greece & 0.304 & 0.503 & $2.3 \%$ & $3.4 \%$ & $1.0 \%$ & $1.0 \%$ & $1.1 \%$ & 15,070 & 17,765 & $0.7 \%$ & $3.5 \%$ & $-2.6 \%$ & $-4.1 \%$ & $1.2 \%$ & 0.768 & 0.872 & $0.6 \%$ & $0.8 \%$ & $0.3 \%$ & $0.3 \%$ & $0.3 \%$ \\
\hline & 0.460 & 0.381 & $-0.8 \%$ & $-0.1 \%$ & $-1.6 \%$ & $-2.4 \%$ & $-0.2 \%$ & 6,756 & 12,554 & $2.7 \%$ & $3.6 \%$ & $1.8 \%$ & $0.4 \%$ & $4.1 \%$ & 0.741 & 0.845 & $0.6 \%$ & $0.8 \%$ & $0.3 \%$ & $0.3 \%$ & $0.4 \%$ \\
\hline and & 514 & 0.579 & $0.5 \%$ & $3.6 \%$ & $-3.0 \%$ & $-4.6 \%$ & $0.8 \%$ & 22,491 & 58,326 & $4.1 \%$ & $5.3 \%$ & $2.7 \%$ & $-0.6 \%$ & $16.6 \%$ & 0.795 & 0.942 & $8 \%$ & $.0 \%$ & $4 \%$ & $.3 \%$ & $1.0 \%$ \\
\hline & 454 & 0.499 & $4 \%$ & $1.8 \%$ & $-1.0 \%$ & $-1.9 \%$ & $0.6 \%$ & 24,814 & 26,729 & $0.3 \%$ & $3 \%$ & $-0.7 \%$ & $-1.9 \%$ & $1.3 \%$ & 0.800 & 0.883 & $1.4 \%$ & $.7 \%$ & $2 \%$ & $1 \%$ & $3 \%$ \\
\hline Latvia & 263 & 0.406 & $1.9^{\circ}$ & $3.3 \%$ & $0.4 \%$ & $-1.0 \%$ & $2.8 \%$ & 3,824 & 12,132 & $5.1 \%$ & & $1.6 \%$ & $0.1 \%$ & 4.2 & 0.673 & 0.854 & $1.0 \%$ & $6 \%$ & & $0.3 \%$ & $0.5 \%$ \\
\hline Lithuania & 0.424 & 0.463 & $0.4 \%$ & $-0.2 \%$ & $1.0 \%$ & $0.5 \%$ & $1.8 \%$ & 3,999 & 13,279 & $5.4 \%$ & $7.7 \%$ & $2.9 \%$ & $2.1 \%$ & $4.3 \%$ & 0.703 & 0.869 & $0.9 \%$ & $1.4 \%$ & $0.5 \%$ & $0.4 \%$ & $0.5 \%$ \\
\hline Luxembourg & 0.592 & 0.616 & $0.2 \%$ & $1.4 \%$ & $-1.1 \%$ & $-1.4 \%$ & $-0.7 \%$ & 56,874 & 84,410 & $1.7 \%$ & $3.4 \%$ & $-0.1 \%$ & $-0.8 \%$ & $1.1 \%$ & 0.817 & 0.909 & $0.5 \%$ & $0.7 \%$ & $0.2 \%$ & $0.1 \%$ & $0.4 \%$ \\
\hline Netherlands & 0.541 & 0.513 & $-0.2 \%$ & $1.0 \%$ & $-1.5 \%$ & $-1.9 \%$ & $-0.8 \%$ & 29,268 & 41,666 & $1.5 \%$ & $2.5 \%$ & $0.6 \%$ & $-0.2 \%$ & $1.9 \%$ & 0.862 & 0.934 & $0.3 \%$ & $0.4 \%$ & $0.3 \%$ & $0.3 \%$ & $0.2 \%$ \\
\hline Portugal & 0.353 & 0.507 & $1.6 \%$ & $2.5 \%$ & $0.7 \%$ & $-0.6 \%$ & $3.0 \%$ & 13,659 & 18,101 & $1.2 \%$ & $2.0 \%$ & $0.4 \%$ & $-0.9 \%$ & $2.8 \%$ & 0.760 & 0.850 & $0.5 \%$ & $0.5 \%$ & $0.4 \%$ & $0.5 \%$ & $0.3 \%$ \\
\hline Romania & 0.342 & 0.271 & $-1.0 \%$ & $1.0 \%$ & $-3.2 \%$ & $-6.1 \%$ & $2.2 \%$ & 3,692 & 8,715 & $3.8 \%$ & $4.1 \%$ & $3.5 \%$ & $2.3 \%$ & $5.6 \%$ & 0.687 & 0.816 & $0.8 \%$ & $1.1 \%$ & $0.4 \%$ & $0.4 \%$ & $0.4 \%$ \\
\hline Slovakia & 0.295 & 0.414 & $1.5 \%$ & $0.0 \%$ & $3.2 \%$ & $1.2 \%$ & $6.7 \%$ & 6,600 & 15,564 & $3.8 \%$ & $5.1 \%$ & $2.4 \%$ & $1.8 \%$ & $3.4 \%$ & 0.751 & 0.857 & $0.6 \%$ & $0.7 \%$ & $0.5 \%$ & $0.5 \%$ & $0.4 \%$ \\
\hline Slovenia & 0.596 & 0.488 & $-0.9 \%$ & $-1.0 \%$ & $-0.7 \%$ & $-2.8 \%$ & $3.1 \%$ & 11,435 & 20,216 & $2.5 \%$ & $4.2 \%$ & $0.7 \%$ & $-0.8 \%$ & $3.5 \%$ & 0.782 & 0.902 & $0.6 \%$ & $0.9 \%$ & $0.3 \%$ & $0.2 \%$ & $0.4 \%$ \\
\hline Spain & 0.506 & 0.476 & $-0.3 \%$ & $1.2 \%$ & $-1.8 \%$ & $-3.7 \%$ & $1.5 \%$ & 17,961 & 24,913 & $1.4 \%$ & $2.7 \%$ & $0.1 \%$ & $-1.5 \%$ & $2.9 \%$ & 0.800 & 0.893 & $0.5 \%$ & $0.5 \%$ & $0.4 \%$ & $0.4 \%$ & $0.4 \%$ \\
\hline & & & & & $-1.0 \%$ & & $-0.5 \%$ & 28,446 & 44,045 & $1.9 \%$ & $3.0 \%$ & $0.8 \%$ & $0.3 \%$ & $1.6 \%$ & 0.857 & 0.937 & $0.4 \%$ & $0.5 \%$ & $0.3 \%$ & $0.4 \%$ & $0.2 \%$ \\
\hline U.K. & 0.499 & 0.465 & $-0.3 \%$ & $1.1 \%$ & $-1.8 \%$ & $-2.3 \%$ & $-1.0 \%$ & 23,176 & 32,777 & $1.5 \%$ & $2.6 \%$ & $0.4 \%$ & $0.0 \%$ & $1.1 \%$ & 0.839 & 0.920 & $0.4 \%$ & $0.5 \%$ & $0.3 \%$ & $0.4 \%$ & $0.1 \%$ \\
\hline
\end{tabular}

This table presents the initial value, the final value and the average rates of growth of the variables for the indicated periods. 
Table A.2. Testing for unit roots. Per capita MSW

\begin{tabular}{|c|c|c|c|c|c|c|c|c|c|c|}
\hline & ADF-GLS & CKP1 & TB1 & CKP2 & TB1 & TB2 & CKP3 & TB1 & TB2 & TB3 \\
\hline EU27 & -1.56 & -2.26 & 2000 & $-3.72 *$ & 2003 & 2010 & $-6.72 * *$ & 2003 & 2008 & 2014 \\
\hline Austria & -0.90 & $-4.27 * *$ & 2000 & $-4.48 * *$ & 1998 & 2004 & $-5.73 * *$ & 1998 & 2004 & 2010 \\
\hline Belgium & -0.56 & -2.87 & 2008 & $-7.83 * *$ & 2007 & 2016 & $-10.37 * *$ & 1999 & 2008 & 2015 \\
\hline Bulgaria & -1.86 & $-4.37 * *$ & 2011 & $-5.19 * *$ & 1998 & 2011 & $-5.96 * *$ & 1998 & 2009 & 2013 \\
\hline Cyprus & -1.56 & -2.42 & 2010 & -2.54 & 2010 & 2015 & $-6.65 * *$ & 2001 & 2010 & 2015 \\
\hline Czechia & -1.92 & $-3.43 * *$ & 2001 & $-5.52 * *$ & 2001 & 2012 & $-4.81 * *$ & 1998 & 2001 & 2012 \\
\hline Denmark & -0.48 & $-6.98 * *$ & 2007 & $-4.49 * *$ & 2009 & 2012 & $-8.08 * *$ & 2003 & 2009 & 2012 \\
\hline Estonia & -1.70 & $-4.85 * *$ & 2009 & $-5.75 * *$ & 2007 & 2011 & $-5.26 * *$ & 2001 & 2008 & 2012 \\
\hline France & -1.01 & $-3.13 *$ & 2008 & -2.32 & 2003 & 2008 & $-4.33 * *$ & 2003 & 2007 & 2016 \\
\hline Germany & -1.68 & -2.86 & 2003 & -3.21 & 2003 & 2007 & $-5.08 * *$ & 2003 & 2007 & 2016 \\
\hline Greece & -1.51 & $-3.13 *$ & 2010 & -3.12 & 1999 & 2010 & $-5.30 * *$ & 1999 & 2010 & 2013 \\
\hline Hungary & -1.57 & $-3.25^{*}$ & 2010 & -2.77 & 2000 & 2010 & $-5.34 * *$ & 2000 & 2008 & 2012 \\
\hline Ireland & -1.15 & -2.10 & 2008 & $-4.05 * *$ & 2007 & 2010 & $-4.58 * *$ & 2001 & 2006 & 2011 \\
\hline Italy & -1.13 & -2.05 & 2007 & -2.96 & 2007 & 2012 & -3.19 & 1999 & 2007 & 2012 \\
\hline Latvia & -2.46 & $-4.15 * *$ & 2010 & $-4.11 * *$ & 2007 & 2011 & $-5.66 * *$ & 2001 & 2007 & 2011 \\
\hline Lithuania & -0.79 & $-4.41 * *$ & 1999 & $-4.03 * *$ & 1999 & 2009 & $-4.79 * *$ & 1999 & 2009 & 2013 \\
\hline Luxembourg & -0.68 & -2.95 & 2009 & $-3.50 *$ & 2008 & 2013 & $-6.09 * *$ & 1998 & 2009 & 2013 \\
\hline Poland & -3.17 & -2.43 & 2005 & -2.09 & 2001 & 2005 & $-5.65 * *$ & 2001 & 2005 & 2014 \\
\hline Portugal & -2.48 & $-3.11 *$ & 2012 & $-4.49 * *$ & 2002 & 2012 & $-5.28 * *$ & 2001 & 2008 & 2012 \\
\hline Romania & -1.53 & -2.91 & 2010 & $-4.83 * *$ & 2009 & 2012 & $-6.58 * *$ & 1999 & 2009 & 2012 \\
\hline Slovakia & -1.01 & -2.07 & 2015 & $-3.61 *$ & 2002 & 2016 & $-5.63 * *$ & 2002 & 2008 & 2015 \\
\hline Slovenia & -2.74 & -1.94 & 2004 & -3.13 & 2004 & 2011 & $-3.97 *$ & 2002 & 2009 & 2013 \\
\hline Spain & -1.95 & -1.20 & 2000 & -2.67 & 2002 & 2014 & $-6.19 * *$ & 2000 & 2008 & 2014 \\
\hline Sweden & -0.95 & $-3.69 * *$ & 2007 & $-4.88 * *$ & 2008 & 2011 & $-5.87 * *$ & 1999 & 2008 & 2011 \\
\hline U. Kingdom & -1.07 & -1.72 & 2002 & $-3.73^{*}$ & 2004 & 2013 & $-6.28 * *$ & 2002 & 2007 & 2013 \\
\hline
\end{tabular}

ADF-GLS is the statistic proposed by Elliot et al. (1996) when the specification includes an intercept and a deterministic trend. CKPi is the ADF type statistic proposed by Carrion-i-Silvestre $e t$ al. (2009) when the specification includes i breaks that affect both the intercept and the deterministic trend, with $\mathrm{i}=1,2,3$.

** rejection of the unit root null hypothesis for a $5 \%$ significance level

*: rejection of the unit root null hypothesis for a $10 \%$ significance level 
Table A.3. Testing for unit roots. Per capita GDP

\begin{tabular}{|c|c|c|c|c|c|c|c|c|c|c|}
\hline & ADF-GLS & CKP1 & TB1 & CKP2 & TB1 & TB2 & CKP3 & TB1 & TB2 & TB3 \\
\hline EU27 & -1.33 & -2.24 & 2009 & $-3.50^{*}$ & 2009 & 2013 & $-5.47 * *$ & 2003 & 2009 & 2013 \\
\hline Austria & -0.91 & -2.43 & 2009 & -3.12 & 2003 & 2009 & $-4.16 * *$ & 2003 & 2009 & 2013 \\
\hline Belgium & -1.26 & $-3.43 * *$ & 2009 & $-4.15 * *$ & 2009 & 2013 & $-6.85 * *$ & 2002 & 2009 & 2013 \\
\hline Bulgaria & -2.25 & -1.99 & 1999 & $-3.88 * *$ & 2001 & 2009 & $-8.16 * *$ & 2001 & 2009 & 2014 \\
\hline Cyprus & -2.33 & -1.51 & 2009 & $-4.37 * *$ & 2009 & 2014 & $-4.56 * *$ & 2009 & 2011 & 2014 \\
\hline Czechia & -2.28 & -1.76 & 2009 & -2.39 & 2003 & 2009 & $-4.15 * *$ & 2003 & 2009 & 2013 \\
\hline Denmark & -1.98 & -2.91 & 2009 & -3.33 & 2009 & 2014 & $-4.64 * *$ & 2002 & 2009 & 2014 \\
\hline Estonia & -1.54 & -2.74 & 2009 & -2.57 & 2006 & 2009 & $-3.85^{*}$ & 2003 & 2007 & 2009 \\
\hline France & -1.11 & -2.17 & 2009 & -3.01 & 2000 & 2009 & $-4.41 * *$ & 2000 & 2009 & 2014 \\
\hline Germany & -1.13 & -2.94 & 2009 & -2.55 & 2009 & 2012 & $-5.23 * *$ & 2003 & 2009 & 2012 \\
\hline Greece & -2.35 & -1.94 & 2009 & -2.20 & 2008 & 2013 & $-6.40 * *$ & 2003 & 2008 & 2013 \\
\hline Hungary & -1.71 & -2.21 & 2009 & -3.39 & 2009 & 2013 & -3.41 & 1998 & 2009 & 2013 \\
\hline Ireland & -1.50 & -2.76 & 2009 & $-3.56^{*}$ & 2008 & 2015 & $-4.77 * *$ & 2000 & 2008 & 2015 \\
\hline Italy & -1.46 & -2.06 & 2009 & $-3.49 *$ & 2008 & 2015 & $-4.54 * *$ & 2000 & 2009 & 2014 \\
\hline Latvia & -1.65 & -2.41 & 2009 & $-6.49 * *$ & 2002 & 2009 & $-3.84 *$ & 2003 & 2008 & 2010 \\
\hline Lithuania & -2.26 & -2.10 & 2009 & $-4.57 * *$ & 2002 & 2009 & $-4.30 * *$ & 2002 & 2007 & 2009 \\
\hline Luxembourg & -0.87 & $-3.39 *$ & 2009 & $-5.09 \% *$ & 1999 & 2009 & $-4.39 * *$ & 2000 & 2007 & 2009 \\
\hline Poland & -1.17 & -2.06 & 2006 & $-3.60 *$ & 2007 & 2016 & $-5.24 * *$ & 2002 & 2007 & 2016 \\
\hline Portugal & -1.90 & -1.15 & 2000 & $-3.83 *$ & 2001 & 2012 & $-6.15 * *$ & 2000 & 2007 & 2014 \\
\hline Romania & -2.12 & -1.86 & 1999 & -2.83 & 2001 & 2010 & -3.75 & 2001 & 2008 & 2012 \\
\hline Slovakia & -2.14 & -2.23 & 2007 & -3.47 & 2004 & 2009 & $-4.34 * *$ & 2004 & 2009 & 2013 \\
\hline Slovenia & -1.70 & -1.34 & 2009 & -2.84 & 2009 & 2015 & $-4.99 * *$ & 2005 & 2009 & 2014 \\
\hline Spain & -2.02 & -1.95 & 2009 & -2.72 & 2007 & 2013 & $-6.33 * *$ & 2000 & 2007 & 2013 \\
\hline Sweden & -1.06 & $-3.83 * *$ & 2009 & -3.31 & 2008 & 2010 & $-3.61 *$ & 2008 & 2010 & 2012 \\
\hline U. Kingdom & -1.49 & $-3.13 *$ & 2009 & -2.69 & 2007 & 2009 & $-4.29 * *$ & 2000 & 2008 & 2010 \\
\hline
\end{tabular}

ADF-GLS is the statistic proposed by Elliot et al. (1996) when the specification includes an intercept and a deterministic trend. CKPi is the ADF type statistic proposed by Carrion-i-Silvestre $e t$ al. (2009) when the specification includes i breaks that affect both the intercept and the deterministic trend, with $\mathrm{i}=1,2,3$.

**: rejection of the unit root null hypothesis for a $5 \%$ significance level

*: rejection of the unit root null hypothesis for a $10 \%$ significance level 
Table A.4. Testing for unit roots. HDI

\begin{tabular}{|c|c|c|c|c|c|c|c|c|c|c|}
\hline & ADF-GLS & CKP1 & TB1 & CKP2 & TB1 & TB2 & CKP3 & TB1 & TB2 & TB3 \\
\hline Austria & -1.67 & $-4.52 * *$ & 2007 & $-4.78 * *$ & 2002 & 2007 & $-4.66 * *$ & 2001 & 2003 & 2007 \\
\hline Belgium & -1.11 & $-3.94 * *$ & 2008 & $-3.57 *$ & 1998 & 2006 & $-6.37 * *$ & 1998 & 2006 & 2009 \\
\hline Bulgaria & -1.78 & $-3.23^{*}$ & 2003 & $-3.84^{*}$ & 2001 & 2009 & $-6.02 * *$ & 2001 & 2009 & 2015 \\
\hline Cyprus & -1.97 & -2.81 & 2010 & $-3.98 * *$ & 2002 & 2010 & $-5.70 * *$ & 2002 & 2010 & 2015 \\
\hline Czechia & -0.48 & $-4.41 * *$ & 2007 & $-3.87 * *$ & 1998 & 2007 & $-4.86 * *$ & 1998 & 2004 & 2007 \\
\hline Denmark & -0.71 & $-3.26^{*}$ & 2003 & $-3.62 *$ & 2005 & 2011 & $-8.49 * *$ & 2001 & 2005 & 2011 \\
\hline Estonia & -0.89 & $-3.30 *$ & 2005 & $-4.83 * *$ & 2001 & 2008 & $-8.21 * *$ & 2001 & 2007 & 2011 \\
\hline Finland & -0.78 & -3.09 & 2004 & -3.48 & 2001 & 2004 & -3.55 & 2001 & 2004 & 2009 \\
\hline Germany & -0.30 & $-4.63 * *$ & 2006 & $-4.20 * *$ & 2004 & 2006 & $-4.16 * *$ & 1998 & 2004 & 2006 \\
\hline Greece & -1.03 & $-3.64 * *$ & 2005 & $-3.76 * *$ & 1999 & 2006 & $-5.93 * *$ & 2001 & 2006 & 2011 \\
\hline Hungary & -0.76 & $-4.11 * *$ & 2006 & $-5.00 * *$ & 1998 & 2007 & $-4.95 * *$ & 1998 & 2007 & 2011 \\
\hline Ireland & -1.76 & -1.39 & 1998 & $-3.78 *$ & 1998 & 2009 & -3.77 & 1998 & 2006 & 2010 \\
\hline Italy & -1.08 & -2.86 & 2007 & $-4.72 * *$ & 2006 & 2013 & $-5.55 * *$ & 2001 & 2007 & 2013 \\
\hline Latvia & -1.44 & -2.89 & 2006 & $-4.22 * *$ & 2007 & 2010 & $-5.98 * *$ & 2001 & 2006 & 2010 \\
\hline Lithuania & -1.05 & $-3.35 *$ & 2009 & $-5.30 * *$ & 2006 & 2009 & $-6.87 * *$ & 2006 & 2009 & 2014 \\
\hline Luxembourg & -0.83 & -2.86 & 2001 & -3.26 & 1999 & 2009 & $-5.74 * *$ & 1999 & 2009 & 2013 \\
\hline Netherlands & -1.92 & -2.70 & 2011 & $-5.36 * *$ & 2006 & 2011 & $-4.97 * *$ & 2005 & 2008 & 2011 \\
\hline Portugal & -2.01 & -2.36 & 1999 & -2.87 & 1999 & 2013 & $-5.15 * *$ & 1999 & 2004 & 2013 \\
\hline Romania & -1.88 & -2.12 & 2008 & -2.74 & 2002 & 2008 & $-4.76 * *$ & 2002 & 2008 & 2012 \\
\hline Slovakia & -1.98 & -2.54 & 2007 & -3.25 & 2003 & 2009 & $-5.29 * *$ & 2003 & 2009 & 2012 \\
\hline Slovenia & -0.61 & $-3.28 *$ & 2005 & $-4.18 * *$ & 2005 & 2012 & $-5.80 * *$ & 2003 & 2009 & 2012 \\
\hline Spain & -1.27 & $-3.38^{*}$ & 2010 & $-3.66^{*}$ & 2000 & 2005 & $-4.29 * *$ & 2000 & 2005 & 2010 \\
\hline Sweden & -1.90 & -2.61 & 2004 & $-4.92 * *$ & 2000 & 2013 & $-4.57 * *$ & 1998 & 2004 & 2013 \\
\hline U. Kingdom & -0.93 & $-4.08 * *$ & 2006 & -2.46 & 2011 & 2013 & $-4.81 * *$ & 2006 & 2011 & 2013 \\
\hline
\end{tabular}

ADF-GLS is the statistic proposed by Elliot et al (1996) when the specification includes an intercept and a deterministic trend. CKPi is the ADF type statistic proposed by Carrion-i-Silvestre $e t$ al. (2009) when the specification includes $i$ breaks that affect both the intercept and the deterministic trend, with $i=1,2,3$.

$* *$ : rejection of the unit root null hypothesis for a $5 \%$ significance level

*: rejection of the unit root null hypothesis for a $10 \%$ significance level 
${ }^{1}$ We should also cite the seminal paper of Cole et al. (1997) who study the Kuznets curve for several environmental degradation measures, including waste generation.

${ }^{2}$ We should note that this statement not only concerns waste generation but can also be extended to most measures of environment degradation, as Vadén et al. (2020) and Haberl et al. (2020) note.

${ }^{3}$ Given that the MSW data for 2018 are not available for Cyprus, Greece, and Ireland, the sample covers 1995-2017 for these countries.

${ }^{4}$ MSW data for Ireland are missing for 2013 and 2015 and, therefore, we have linearly interpolated them.

${ }^{5}$ Casini and Perron (2019) provide an excellent review of the recent advances in structural breaks in time series.

${ }^{6}$ We should note that we could relax this restriction and consider the presence of breaks in the variance at different periods than those of the parameter regression. Perron et al. (2020) propose a statistic to analyze this point, based on the procedure defined in Qu and Perron (2008). However, the scarce data availability warns against the use of these statistics. Consequently, we prefer to focus on the analysis of changes in the parameters of the regression and leave the case of changes in the variance for future research, once more observations have been added to the sample.

${ }^{7}$ Additionally, we should take into account that the lack of evidence against the unit root null hypothesis may be related to the relatively short length of the sample.

${ }^{8}$ The values in parentheses represent the elasticities for the estimated segments before and after the GR, respectively. 